\title{
On the Role of Single Regiodefects and Polydispersity in Regioregular Poly(3-hexylthiophene): Defect Distribution, Synthesis of Defect-Free Chains, and a Simple Model for the Determination of Crystallinity
}

Peter Kohn, ${ }^{\dagger}$ Sven Huettner, ${ }^{\ddagger}$ Hartmut Komber, ${ }^{\S}$ Volodymyr Senkovskyy, ${ }^{\S}$ Roman Tkachov, ${ }^{\S}$ Anton Kiriy, ${ }^{\S}$ Richard H. Friend, ${ }^{\ddagger}$ Ullrich Steiner, ${ }^{\dagger}$ Wilhelm T. S. Huck, ${ }^{\perp,} \nabla$ Jens-Uwe Sommer, ${ }^{\S}$ and Michael Sommer*,L,\#

${ }^{\dagger}$ Biological and Soft Systems, Department of Physics, University of Cambridge, J J Thomson Avenue, Cambridge CB3 0HE, U.K.

${ }^{\ddagger}$ Optoelectronics Group, Cavendish Laboratory, University of Cambridge, J J Thomson Avenue, Cambridge CB3 OHE, U.K.

${ }^{\S}$ Leibniz- Institute of Polymer Research Dresden e.V., Hohe Strasse 6, 01069 Dresden, Germany

${ }^{\perp}$ Melville Laboratory for Polymer Synthesis, Lensfield Road, Cambridge CB2 1EW, U.K.

$\nabla_{\text {Radboud University Nijmegen, Heyendaalseweg 135, } 6525 \text { AJ Nijmegen, Netherlands }}$

\section{Supporting Information}

ABSTRACT: Identifying structure formation in semicrystalline conjugated polymers is the fundamental basis to understand electronic processes in these materials. Although correlations between physical properties, structure formation, and device parameters of regioregular, semicrystalline poly(3hexylthiophene) (P3HT) have been established, it has remained difficult to disentangle the influence of regioregularity, polydispersity, and molecular weight. Here we show that the most commonly used synthetic protocol for the synthesis

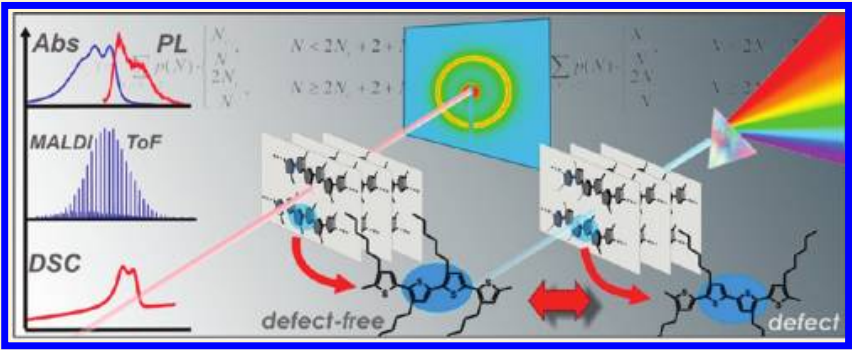
of $\mathrm{P} 3 \mathrm{HT}$, the living Kumada catalyst transfer polycondensation

(KCTP) with $\mathrm{Ni}(\mathrm{dppp}) \mathrm{Cl}_{2}$ as the catalyst, leads to regioregular chains with one single tail-to-tail (TT) defect distributed over the whole chain, in contrast to the hitherto assumed exclusive location at the chain end. NMR end-group analysis and simulations are used to quantify this effect. A series of entirely defect-free P3HT materials with different molecular weights is synthesized via new, soluble nickel initiators. Data on structure formation in defect-free P3HT, as elucidated by various calorimetric and scattering experiments, allow the development of a simple model for estimating the degree of crystallinity. We find very good agreement for predicted and experimentally determined degrees of crystallinities as high as $\sim 70 \%$. For $\mathrm{Ni}\left(\mathrm{dppp}_{\mathrm{P}} \mathrm{Cl}_{2}\right.$-initiated chains comprising one distributed TT unit, the comparison of simulated crystallinities with calorimetric and optical measurements strongly suggests incorporation of the TT unit into the crystal lattice, which is accompanied by an increase in backbone torsion. Polydispersity is identified as a major parameter determining crystallinity within the molecular weight range investigated. We believe that the presented approach and results not only contribute to understanding structure formation in P3HT but are generally applicable to other semicrystalline conjugated polymers as well.

\section{INTRODUCTION}

Regioregular poly(3-hexylthiophene) (rrP3HT) has evolved as a ubiquitous material for organic electronic devices due to its easy availability and tendency to form semicrystalline lamellar microstructures. $^{1-7}$ The power conversion efficiencies of organic photovoltaic devices (OPV) incorporating blends of $\mathrm{rrP} 3 \mathrm{HT}$ and fullerene derivatives have been gradually increased to high values up to $6.48 \%$ during the last years. ${ }^{8-14}$ Films of pristine rr-P3HT are also used in organic field effect transistors (OFETs), which typically yield appreciably high charge carrier mobilities of $10^{-2}$ to $10^{-1} \mathrm{~cm}^{2} /(\mathrm{V} \mathrm{s})$. The performance of such thin film devices critically depends on the microstructure and crystallinity, which in turn is governed by the processing conditions, e.g., the solvent. ${ }^{15}$ Crystallization from poor solvents can lead to very long whiskers, in which the chain can fold back and forth several times along the whisker axis. ${ }^{16}$ Besides processing, molecular parameters such as molecular weight, ${ }^{17-23}$ nature of chain ends, ${ }^{24,25}$ polydispersity, ${ }^{26}$ and regioregularity (RR), i.e., the content of head-to-tail (HT) couplings, ${ }^{27-32}$ influence the optoelectronic properties. The effects of microstructure and ordering on the device performance of P3HT films have been addressed by numerous studies. ${ }^{33-37}$ Generally, a high $\mathrm{RR}$ is important to improve

Received: November 18, 2011

Published: February 14, 2012 
crystallinity and thus device performance: It has been shown that crystal thickness ${ }^{38}$ and crystallinity increase with increasing $\mathrm{RR}^{27,28,33,39}$ and that a large content of tail-to-tail (TT) and head-to-head $(\mathrm{HH})$ couplings, as prevalent in regiorandomP3HT (rran-P3HT), can lead to the complete absence of mainchain crystallinity. ${ }^{31,40}$ Even relatively small variations of $R R$ between $90 \%$ and $96 \%$ can cause major changes in device performance. $^{28,33}$ These results were explained by the fact that higher RRs can improve $\pi-\pi$ stacking and thus twodimensional charge transport. ${ }^{28,33}$ More recent results suggest that photovoltaic blends composed of P3HT may not necessarily require a high $\mathrm{RR}$ for optimum device performance. $^{29,31}$ Despite these general trends, it has remained difficult to assign changes in microstructure or crystallinity to one particular molecular parameter. Therefore, it is still unclear which particular aspect of the microstructure relates to a certain macroscopic electronic property. The difficulty to establish such relationships may arise from imperfect synthetic control over starting materials but also from the inability to isolate the influence of one single molecular parameter on macroscopic properties within a given set of polymers.

One of the most widely used synthetic route to synthesize rrP3HT is the Kumada catalyst transfer polycondensation (KCTP) developed by McCullough et al. $^{5}$ and Yokozawa et al. ${ }^{41}$ This method utilizes the commercially available catalyst (1,3-bis(diphenylphosphino)propane)dichloronickel (Ni$\left.(\mathrm{dppp}) \mathrm{Cl}_{2}\right) \quad 1$ and leads to highly regioregular $\mathrm{P} 3 \mathrm{HT}$ (rrP3HT) with low polydisperities between 1.1 and 1.3. Initiation proceeds from an in situ-formed tail-to-tail (TT) dimer formed from $\mathrm{Ni}(\mathrm{dppp}) \mathrm{Cl}_{2}$ and two monomer molecules, from which propagation of rrP3HT occurs. ${ }^{42,43}$ This TT coupling defect, arising from the structure of the catalyst, is therefore inevitably incorporated into the otherwise regioregular chain. While it was until now assumed that the TT initiating dimer is exclusively located at the beginning of the P3HT chain, a recent study suggests that this might only partially be true: Tkachov et al. observed "random ring walking" when polymerizing P3HT from the external model initiator 4bromobenzene- $\mathrm{Ni}$ (dppe) $-\mathrm{Br}$ and found $\mathrm{P} 3 \mathrm{HT}$ with an internal phenyl group as the major product. ${ }^{44}$ If the same mechanism was operative during the polymerization via commercially available $\mathrm{Ni}(\mathrm{dppp}) \mathrm{Cl}_{2}$, the $\mathrm{TT}$ defect would be located anywhere within the linear P3HT chain. Thus, only the distribution of the TT defect within the chain fully characterizes a P3HT macromolecule.

Independent of the exact location of this TT defect, its influence on microstructure is not clear and cannot be separated from other molecular parameters. It has been suggested that the apparent molecular weight dependence of crystallinity in $\mathrm{P}_{3} \mathrm{HT}^{45,46}$ might be due to terminal TT defects which were considered as noncrystallizable groups. ${ }^{46}$ Polydispersity can affect crystallinity as well, ${ }^{46}$ similar to $n$-alkanes: ${ }^{47,48}$ From a crystal layer comprising shorter and longer chains in a random manner, amorphous ciliae of the longer chains protrude, which limits crystallinity. The situation may become even more complicated if the TT defect is not exclusively located at the chain ends, as the additional question arises if nonterminal TT defects can be incorporated into the crystal lattice. Therefore, it remains challenging to separate the effects of regioregularity and polydispersity unless truly monodisperse or entirely defect-free samples are studied.

We show here that in $\mathrm{Ni}(\mathrm{dppp}) \mathrm{Cl}_{2}$-initiated polymerizations of $\mathrm{P} 3 \mathrm{HT}$ bidirectional growth and reinsertion of $\mathrm{Ni}(0)$ at both ends of the P3HT chain occurs. The resulting distribution of the TT defect within the backbone is characterized by a combination of NMR end group analysis and computer simulations. We further present the synthesis of a series of entirely defect-free P3HT materials with $100 \% \mathrm{RR}$ via new soluble nickel initiators, in which the TT defect is eliminated. The crystallization behavior of the two series, i.e., well-defined, conventionally polymerized samples and well-defined, defectfree samples, is comparatively studied by X-ray scattering and calorimetric and optical experiments. We finally present a simple model for the determination of crystallinity based on the molecular weight distribution. This model quantitatively accounts for experimentally observed crystallinities in defectfree P3HT and corroborates the strong influence of polydispersity on crystallinity. The combination of simulated TT defect distributions, experimental crystallinities, and the model suggests that partial inclusion of tail-to-tail units into the crystal lattice is tolerated.

\section{EXPERIMENTAL SECTION}

Synthetic Procedures. General Procedures and Materials. Solvents and starting materials were obtained from Aldrich unless otherwise noted and used as received. Commercially available dry THF was distilled over sodium and benzophenone ketyl and stored under argon. Diethylbipyridylnickel $\left(\mathrm{Et}_{2} \mathrm{Ni}-\right.$ (bipy)), ${ }^{49}$ 2-bromo-5-chloromagnesio-3-hexylthiophene, ${ }^{50}$ and the conventionally polymerized samples $2 \mathrm{a}-\mathbf{e}$ (route A) ${ }^{42}$ were synthesized through standard literature procedures.

Initiators. Initiator $\mathrm{Ni}(\mathrm{dppe}) \mathrm{ThBr}$ (3a): In a glovebox, $217 \mathrm{mg}$ $(0.88 \mathrm{mmol})$ of 2-bromo-3-hexylthiophene and $8 \mathrm{~mL}$ of dry THF were placed into a $100 \mathrm{~mL}$ flask and sealed with a septum. The flask was transferred outside, and the solution was cooled to $-15{ }^{\circ} \mathrm{C}$. A $200 \mathrm{mg}$ amount of $\mathrm{Et}_{2} \mathrm{Ni}$ (bipy) $(200 \mathrm{mg}, 0.73 \mathrm{mmol})$ was added dropwise in $10 \mathrm{~mL}$ of THF via syringe. The initial green color changed to yellow and finally red, indicating completion of reaction. A $350 \mathrm{mg}$ amount of 1,2-bis(diphenylphosphino)ethane (dppe) was added in $10 \mathrm{~mL}$ in one portion, upon which a slight color change from red to orange-red was observed. A small portion of THF was evaporated, and the mixture was transferred back to the glovebox. Filtration into dry diethyl ether $/ n$-hexanes $1: 2$ yielded a yellow precipitate, which was further crystallized at $-20{ }^{\circ} \mathrm{C}$ overnight. The raw product was redissolved, filtered, and reprecipitated to yield $326 \mathrm{mg}(0.46 \mathrm{mmol}$, $63 \%$ ) of pure, shiny yellow crystals. The ${ }^{1} \mathrm{H}$ and ${ }^{31} \mathrm{P}$ NMR spectra are depicted in Figure SI-1, Supporting Information. For atom numbering, see Scheme $2 .{ }^{1} \mathrm{H}$ NMR (THF- $\left.d_{8}, 303 \mathrm{~K}\right): 8.33\left(\mathrm{~m}, 2 \mathrm{H}, \mathrm{H}_{\mathrm{Ar}}\right), 8.27(\mathrm{~m}$, $\left.2 \mathrm{H}, \mathrm{H}_{\mathrm{Ar}}\right), 7.68\left(\mathrm{~m}, 2 \mathrm{H}, \mathrm{H}_{\mathrm{Ar}}\right), 7.6-7.45\left(6 \mathrm{H}, \mathrm{H}_{\mathrm{Ar}}\right), 7.37\left(3 \mathrm{H}, \mathrm{H}_{\mathrm{Ar}}\right), 7.30$ $\left(\mathrm{t}, 1 \mathrm{H}, \mathrm{H}_{\mathrm{Ar}}\right), 7.08\left(2 \mathrm{H}, \mathrm{H}_{\mathrm{Ar}}\right), 7.07\left(\mathrm{dd},{ }^{2} J_{\mathrm{HH}}=4.8 \mathrm{~Hz}, J_{\mathrm{PH}}=2.1 \mathrm{~Hz}\right.$, $\left.1 \mathrm{H}, \mathrm{H}_{\mathrm{a}}\right), 6.84\left(\mathrm{~m}, 2 \mathrm{H}, \mathrm{H}_{\mathrm{Ar}}\right), 6.40\left(\mathrm{dd},{ }^{2} J_{\mathrm{HH}}=4.8 \mathrm{~Hz}, J_{\mathrm{PH}}=1.4 \mathrm{~Hz}, 1 \mathrm{H}\right.$, $\left.\mathrm{H}_{\mathrm{b}}\right) 2.65-2.45\left(2 \mathrm{H}, \mathrm{H}_{\mathcal{c}} \mathrm{H}_{\alpha \mathrm{CH} 2}\right), 2.4-2.2\left(2 \mathrm{H}, \mathrm{H}_{\mathrm{c}}\right), 1.94(\mathrm{~m}, 1 \mathrm{H}$, $\left.\mathrm{H}_{\alpha \mathrm{CH} 2}\right), 1.61\left(\mathrm{~m}, 1 \mathrm{H}, \mathrm{H}_{\mathrm{c}}\right), 1.54\left(\mathrm{~m}, 1 \mathrm{H}, \mathrm{H}_{\beta \mathrm{CH}}\right), 1.35-1.15(7 \mathrm{H}$, $\left.\mathrm{H}_{\beta \mathrm{CH} 2},\left(\mathrm{CH}_{2}\right)_{3}\right), 0.91 \mathrm{ppm}\left(\mathrm{t}, 3 \mathrm{H}, \mathrm{CH}_{3}\right) .{ }^{31} \mathrm{P}$ NMR $\left(\right.$ THF- $\left.d_{8}, 303 \mathrm{~K}\right)$ : $58.04\left(\mathrm{~d}, J_{\mathrm{PP}}=32.9 \mathrm{~Hz}, \mathrm{P}_{2}\right), 42.58 \mathrm{ppm}\left(\mathrm{d}, J_{\mathrm{PP}}=32.9 \mathrm{~Hz}, \mathrm{P}_{1}\right)$.

Initiator $\mathrm{Ni}(\mathrm{dppp}) \mathrm{ThBr}(\mathbf{3 b})$ : Same procedure as for 3a yielded 301 $\mathrm{mg}(0.42 \mathrm{mmol}, 57 \%)$ of shiny golden crystals. The ${ }^{1} \mathrm{H}$ and ${ }^{31} \mathrm{P}$ NMR spectra are depicted in Figure SI-2, Supporting Information. For atom numbering, see Scheme 2. ${ }^{1} \mathrm{H}$ NMR (THF- $d_{8}, 303 \mathrm{~K}$ ): 8.25 (br, $2 \mathrm{H}$, $\left.\mathrm{H}_{\mathrm{Ar}}\right), 8.09\left(\mathrm{br}, 2 \mathrm{H}, \mathrm{H}_{\mathrm{Ar}}\right), 7.81\left(\mathrm{br}, 2 \mathrm{H}, \mathrm{H}_{\mathrm{Ar}}\right), 7.44\left(\mathrm{br}, 4 \mathrm{H}, \mathrm{H}_{\mathrm{Ar}}\right), 7.35$ $\left(\mathrm{br}, 5 \mathrm{H}, \mathrm{H}_{\mathrm{Ar}}\right), 7.17\left(\mathrm{br}, 1 \mathrm{H}, \mathrm{H}_{\mathrm{Ar}}\right), 7.00\left(\mathrm{br}, 4 \mathrm{H}, \mathrm{H}_{\mathrm{Ar}}\right), 6.85\left(\mathrm{~d}, \mathrm{~J}_{\mathrm{HH}}=4.8\right.$ $\left.\mathrm{Hz}, 1 \mathrm{H}, \mathrm{H}_{\mathrm{a}}\right), 6.14\left(\mathrm{~d}, J_{\mathrm{HH}}=4.8 \mathrm{~Hz}, 1 \mathrm{H}, \mathrm{H}_{\mathrm{b}}\right), 2.85\left(\mathrm{br}, 1 \mathrm{H}, \mathrm{H}_{\alpha \mathrm{CH} 2}\right)$, $2.64\left(\mathrm{br}, 1 \mathrm{H}, \mathrm{H}_{\mathrm{c}}\right), 2.40\left(\mathrm{br}, 1 \mathrm{H}, \mathrm{H}_{\mathrm{c}}\right), 2.26\left(\mathrm{br}, 1 \mathrm{H}, \mathrm{H}_{\mathrm{c}}\right), 2.04(\mathrm{br}, 3 \mathrm{H}$, $\left.\mathrm{H}_{\mathcal{O}} \mathrm{H}_{\mathrm{d}}, \mathrm{H}_{\alpha \mathrm{CH} 2}\right), 1.69\left(\right.$ br, $\left.1 \mathrm{H}, \mathrm{H}_{\beta \mathrm{CH} 2}\right), 1.44\left(\mathrm{~m}, 1 \mathrm{H}, \mathrm{H}_{\mathrm{d}}\right), 1.35-1.25$ $\left(7 \mathrm{H}, \mathrm{H}_{\beta \mathrm{CH}},\left(\mathrm{CH}_{2}\right)_{3}\right), 0.91 \mathrm{ppm}\left(\mathrm{t}, 3 \mathrm{H}, \mathrm{CH}_{3}\right) .{ }^{31} \mathrm{P}$ NMR $\left(\right.$ THF- $d_{8}, 303$ $\mathrm{K}): 18.45\left(\mathrm{~d}, J=62.5 \mathrm{~Hz}, \mathrm{P}_{2}\right),-3.67 \mathrm{ppm}\left(\mathrm{d}, J=62.5 \mathrm{~Hz}, \mathrm{P}_{1}\right)$.

General Polymerization Procedure for Syntheses of Defect-Free P3HT. Syntheses of defect-free P3HT $\mathbf{4 a - 1}$ (route B) was carried out under argon in single flasks equipped with a stir bar and a septum. The concentration of 2-bromo-5-chloromagnesio-3-hexylthiophene in THF was $0.067 \mathrm{mmol} / \mathrm{mL}$. Different amounts of monomer 
(for $[\mathrm{M}] /[\mathrm{I}]$ ratios, see Table SI-1, Supporting Information) were added to solutions of $\mathbf{3 a}$ or $\mathbf{3 b}(\sim 20-40 \mathrm{mg} / \mathrm{mL})$. Polymerizations were carried out at room temperature for several minutes (3a) and for 30-45 $\mathrm{min}(3 \mathbf{b})$. The polymerization was quenched with $5 \mathrm{M} \mathrm{HCl}$; care was taken to avoid precipitation. After the mixture was stirred further for several minutes, methanol was added to precipitate the polymer and the mixture was filtered into an extraction thimble. The solids were extracted with methanol and chloroform, respectively, and the chloroform solution was concentrated to dryness under reduced pressure. Methanol was added, and the solids were collected and dried in vacuo. A compilation of the physical properties of all polymers is given in the Supporting Information. The properties of four polymers studied further in detail are summarized in Table 1.

Table 1. Physical Properties of the Four Samples Studied in Detail $^{a}$

$\begin{array}{lcccc} & \begin{array}{c}\text { 1TT- } \\ \text { P3HT-43 }\end{array} & \begin{array}{c}\text { 0TT- } \\ \text { P3HT-45 }\end{array} & \begin{array}{c}\text { 0TT- } \\ \text { P3HT-65 }\end{array} & \begin{array}{c}\text { 1TT- } \\ \text { P3HT-76 }\end{array} \\ \begin{array}{l}\text { reference to Supporting } \\ \quad \text { Information }\end{array} & \mathbf{2 c} & \mathbf{4 i} & \mathbf{4 f} & \mathbf{2 e} \\ \text { TT defect } & 1 & 0 & 0 & 1 \\ M_{\mathrm{n}}(\mathrm{GPC})[\mathrm{kg} / \mathrm{mol}] & 11.8 & 13.4 & 17.2 & 21.2 \\ \text { PDI (GPC) } & 1.13 & 1.11 & 1.26 & 1.28 \\ M_{\mathrm{n}, \mathrm{MALDI}}[\mathrm{kg} / \mathrm{mol}] & 6.9 & 7.5 & 10.5 & -{ }^{b} \\ \text { PDI }(\mathrm{MALDI}) & 1.022 & 1.020 & 1.028 & -{ }^{b} \\ \text { DP }(\mathrm{MALDI}) & 41 & 45 & 63 & -{ }^{b} \\ \text { DP }(\mathrm{NMR}) & 43 & 45 & 65 & 76 \\ d_{100}[\mathrm{~nm}]\left(190{ }^{\circ} \mathrm{C}\right) & 1.82 & 1.81 & 1.82 & 1.83 \\ d_{002 / 020}[\mathrm{~nm}]\left(190^{\circ} \mathrm{C}\right) & 0.38 & 0.38 & 0.38 & 0.38\end{array}$

${ }^{a}$ 1TT-P3HT-43 denotes a sample with one distributed TT defect (initiated by $\mathrm{Ni}(\mathrm{dppp}) \mathrm{Cl}_{2}$ ) with a degree of polymerization (DP) of 43. $M_{n, G P C}$ was obtained from calibration with polystyrene standards, $M_{\mathrm{n}, \mathrm{MALDI}}$ was calculated from the peak intensities, $\mathrm{DP}_{\text {MALDI }}=$ $M_{\mathrm{n}, \mathrm{MALDI}} /(166.3 \mathrm{~g} / \mathrm{mol}){ }^{{ }^{b}}$ The high molecular weight of 1TT-P3HT76 resulted in a noisy MALDI spectrum and therefore was not used to calculate molecular weights.

\section{RESULTS AND DISCUSSION}

3.1. Defect Distribution of $\mathrm{Ni}(\mathrm{dppp}) \mathrm{Cl}_{2}$-Initiated Poly(3-hexylthiophene). $\mathrm{Ni}(\mathrm{dppp}) \mathrm{Cl}_{2} \mathbf{1}$ or $\mathrm{Ni}(\mathrm{dppe}) \mathrm{Cl}_{2}$ are common catalysts used for the synthesis of regioregular P3HT via KCTP. This method developed by McCullough et al. uses a 70:30 to 80:20 mixture of "regular" 2-bromo-5chloromagnesio-3-hexylthiophene and "reversed" 5-bromo-2chloromagnesio-3-hexylthiophene, respectively, ${ }^{42}$ while Yokozawa and co-workers use pure "regular" 2-bromo-5-chloromagnesio3-hexylthiophene as the active monomer. ${ }^{43,50}$ Catalysts such as $\mathbf{1}$ are usually used, which are highly selective toward polymerization of the regular monomer, and thus the two methods result in the same chain topology and regioregularity. The "reversed monomer" 5-bromo-2-chloromagnesio-3hexylthiophene only polymerizes under specific conditions such as additional lithium chloride, ${ }^{51-53}$ which causes a lower RR. However, such conditions were not used here, and therefore the control materials $\mathbf{2 a}-\mathbf{e}$ obtained from $\mathbf{1}$ are fully regioregular P3HT chains with exactly one tail-to-tail (TT) defect. With the regioregularity (RR) being defined as the percentage of head-to-tail linkages, we can expect RR values from these protocols according to $\mathrm{RR}=(\mathrm{DP}-2) /(\mathrm{DP}-1)$, where $\mathrm{DP}$ is the degree of polymerization. The single TT regiodefect arises from the initial reduction of $\mathrm{Ni}(\mathrm{dppp}) \mathrm{Cl}_{2}$ with 2 equiv of active monomer. ${ }^{42,43}$ Until now it was assumed that chain propagation proceeds unidirectionally from one side of this initiating TT-dimer. ${ }^{5,43}$ We show that, in accordance with recent results from Tkachov et al., ${ }^{44}$ insertion of $\mathrm{Ni}(0)$ occurs at both sides of the initially formed symmetric tail-to-tail dimer at all times of polymerization, resulting in bidirectional growth of the P3HT chain. This leads to an effective "migration" of the TT defect into the backbone from the very beginning and during all times of polymerization, and finally leads to a distribution of the TT defect within the chain (Scheme 1a).

End group analysis of the ${ }^{1} \mathrm{H}$ NMR spectra was used to distinguish between chains with a terminal defect and chains with an internal one. Figure 1a shows the spectrum of the low molecular weight sample 2a with all important assignments. As evidenced by correlations to 2-bromothiophene carbons at about $108 \mathrm{ppm}$ in the HMBC spectrum, all signals in the 6.86$6.81 \mathrm{ppm}$ region arise from protons of bromine end groups (Figure SI-3, Supporting Information). The assignment of the singlet at $6.86 \mathrm{ppm}\left(\mathrm{H}_{2}\right)$ and the singlet of equal intensity at $6.93 \mathrm{ppm}\left(\mathrm{H}_{3}\right)$ to the TT end-group carrying bromine was accomplished by a combination of $1 \mathrm{D}$ and $2 \mathrm{D}$ NMR techniques. The ${ }^{13} \mathrm{C}$ signal assignment is given in the Supporting Information. The well-known signal of bromine caps of regioregular end groups $\left(\mathrm{H}_{10}\right)$ appears at $6.84 \mathrm{ppm}$. The signals at the low frequency side of $\mathrm{H}_{10}$ also result from bromine end-groups and are therefore thought to arise from bromine chain ends with the TT defect being at the second and third position. The signals at 6.90 and $6.80 \mathrm{ppm}$ show a broadening due to coupling to the $\alpha-\mathrm{CH}_{2}$ group of the hexyl residue typical for $\mathrm{H}$ termination. Whereas the first signal is known as $\mathrm{H}_{7}$ of regioregular $\mathrm{P} 3 \mathrm{HT}$, the low field signal is assigned to $\mathrm{H}_{4}$ of a terminal TT group carring hydrogen at the end. This signal indicates that also the Br-TT end can be converted into an initiating side by random ring walking of $\mathrm{Ni}(0)$, which starts chain growth at the other side of the polymer chain. The thus-produced TT defect within the chain is characterized by a proton signal at $7.00 \mathrm{ppm}$, in accordance with the well-known chemical shift for a HT-TT triad. ${ }^{54,55}$ This peak on top of the backbone signal is hard to quantify (see arrow in Figure 1a). However, by comparing the signal intensity of $\mathrm{H}_{2}$ with the intensity of the other bromine end group signals between 6.85 and $6.81 \mathrm{ppm}$, we find that the percentage of chains having the TT defect at the end $(y=0$, see Scheme 1, denoted as TT-P3HT) is already low for small molecular weights of several $\mathrm{kg} / \mathrm{mol}$ and further decreases with increasing degree of polymerization. Figure $2 b$ displays this behavior. Only $28 \%$ of the chains in the low molecular weight control sample $2 \mathrm{a}\left(M_{\mathrm{n}, \mathrm{GPC}}=4.2 \mathrm{~kg} / \mathrm{mol}, \mathrm{DP}_{\mathrm{NMR}}=17\right)$ carry the TT unit at the chain end. This fraction decreases to $18 \%$ for sample $2 \mathrm{e}$ $\left(M_{\mathrm{n}, \mathrm{GPC}}=21.2 \mathrm{~kg} / \mathrm{mol}, \mathrm{DP}=76\right)$. The decrease of the chains having the terminal defect with increasing molecular weight is more pronounced compared to the analogous bifunctional phenyl-based initiator from Tkachov et al., which can be understood as a result from the higher reactivity of the bromine-thiophene bond toward $\mathrm{Ni}(0)$ in comparison to the bromine-phenyl bond. ${ }^{44}$ The same end group signals were also used to estimate the molecular weight, which is more precise and consistent than GPC or MALDI-based values. ${ }^{34}$ Values for the degree of polymerization therefore refer to NMR-based values, unless otherwise stated.

${ }^{1} \mathrm{H}$ NMR end group analysis can only distinguish between the two cases where the TT unit is either located at the end of the chain or anywhere else. In order to reveal the distribution of 


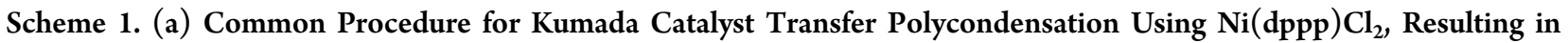
Regioregular P3HT 2a-e with One TT Defect Being Distributed within the Chain. ${ }^{a}$ (b) Hexylthiophene-Based Nickel Initiators $\mathrm{NiL}_{2} \mathrm{ThBr} 3 \mathrm{a}, \mathrm{b}\left(\mathrm{L}_{2}=\right.$ dppe, dppp) for the Synthesis of Defect-Free P3HT

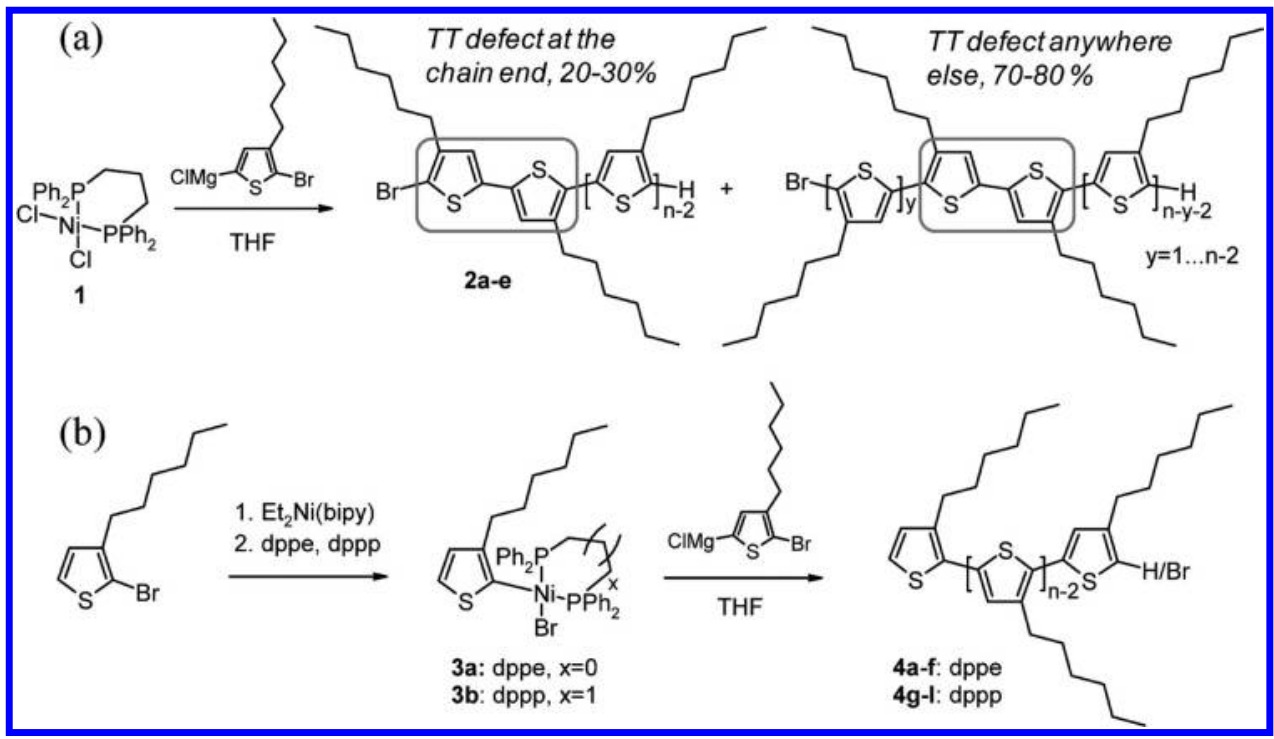

${ }^{a}$ The fraction of chains with a terminal TT unit is a function of the degree of polymerization.

${ }^{b}$ Samples $\mathbf{4 a}-\mathbf{f}$ and $\mathbf{4 g}-\mathbf{i}$ are polymerized starting from $\mathbf{3 a}$ and $\mathbf{3 b}$, respectively.

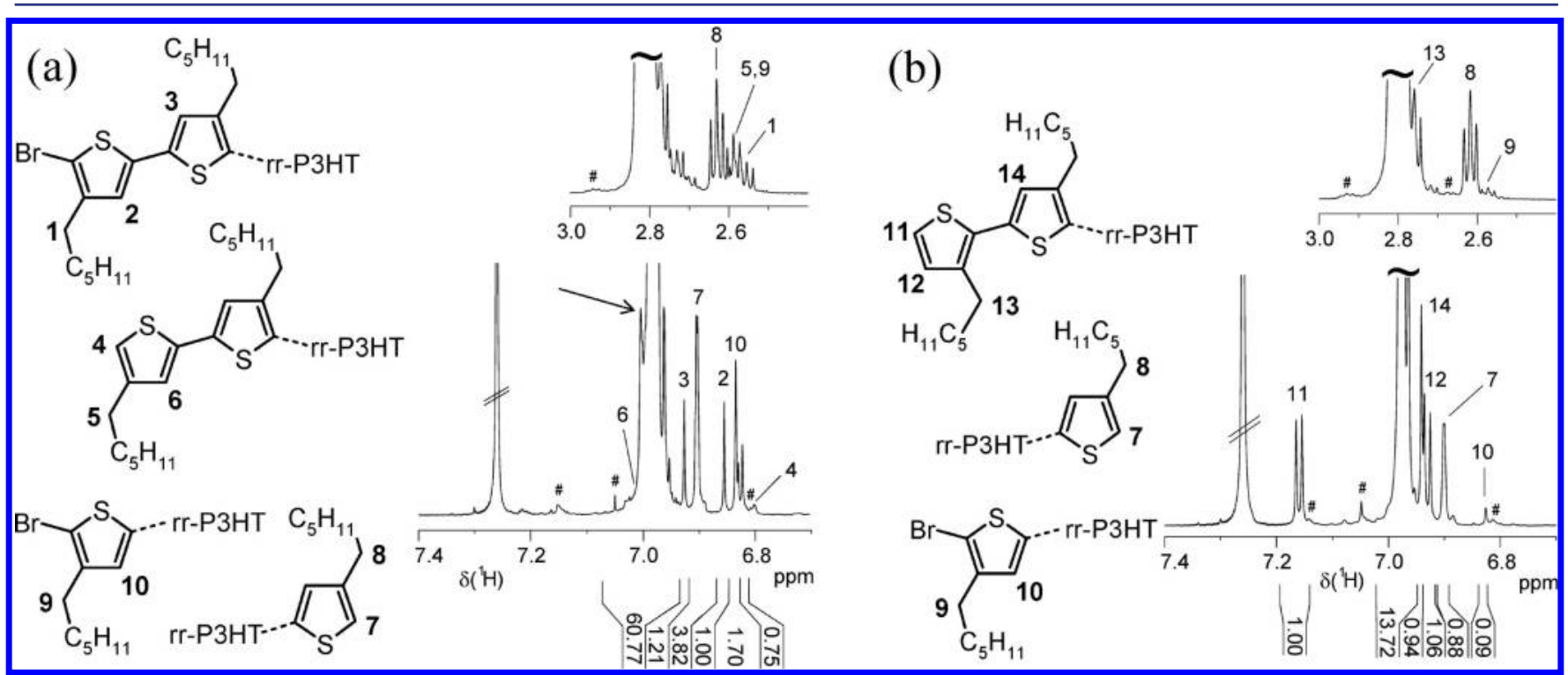

Figure 1. ${ }^{1} \mathrm{H}$ NMR end group analysis of P3HT. (a) Proton assignments of Ni(dppp) $\mathrm{Cl}_{2}$-initiated P3HT and ${ }^{1} \mathrm{H}$ NMR spectrum (regions) of sample 2a $\left(\mathrm{DP}=18\right.$, solvent: $\mathrm{CDCl}_{3} ;{ }^{13} \mathrm{C}$ satellite signals marked by \#). The signals at the lower frequency side of $\mathrm{H}_{10}$ presumably arise from bromine-terminated chains with the TT defect being at the second and third position. The signal marked by an arrow is assigned to the two protons of the TT unit in a TH-TT-HT sequence (TT within the chain). (b) Proton assignments and ${ }^{1} \mathrm{H}$ NMR end-group analysis of the low molecular weight defect-free P3HT sample $4 a\left(D P=16\right.$, solvent: $\mathrm{CDCl}_{3} ;{ }^{13} \mathrm{C}$ satellite signals are marked by \#).

the TT unit within the chain, the mechanism of KCTP was simulated according to a recently presented model. ${ }^{44}$ Here, random hopping of the nickel catalyst on the conjugated backbone together with a stickiness $\delta$ when $\mathrm{Ni}(0)$ approaches the chain end is assumed (Figure 2a). The parameter $\delta$ introduces a unidirectional component to the random walk. The propability to jump to a bromine end group is therefore biased compared to the otherwise random walk (jump probabilities to the right and left are 0.5 if $\mathrm{Ni}(0)$ is located somewhere on the chain). The biased probabilities for $\mathrm{Ni}(0)$ to insert at chain ends lead to a higher probability to find Ni there, i.e., $\mathrm{Ni}$ appears to "stick" at the chain ends to a degree determined by $\delta$. Using this model, the fraction of terminal TT defects can be simulated with $\delta$ being the only parameter. Best agreement of the model with the experimental values (circles in Figure $2 \mathrm{~b}$ ) was achieved for $\delta=0.55$ (line in Figure 2b). In order to investigate possible influences of the ligand on the "ring walking" behavior and thus on the distribution of the TT defect, additional samples were polymerized with $\mathrm{Ni}(\mathrm{dppe}) \mathrm{Cl}_{2}$. However, although dppe imparts different reaction rates and catalytic resting states compared to dppp, ${ }^{56}$ the fractions of chains with terminal TT units were always the same for a given 

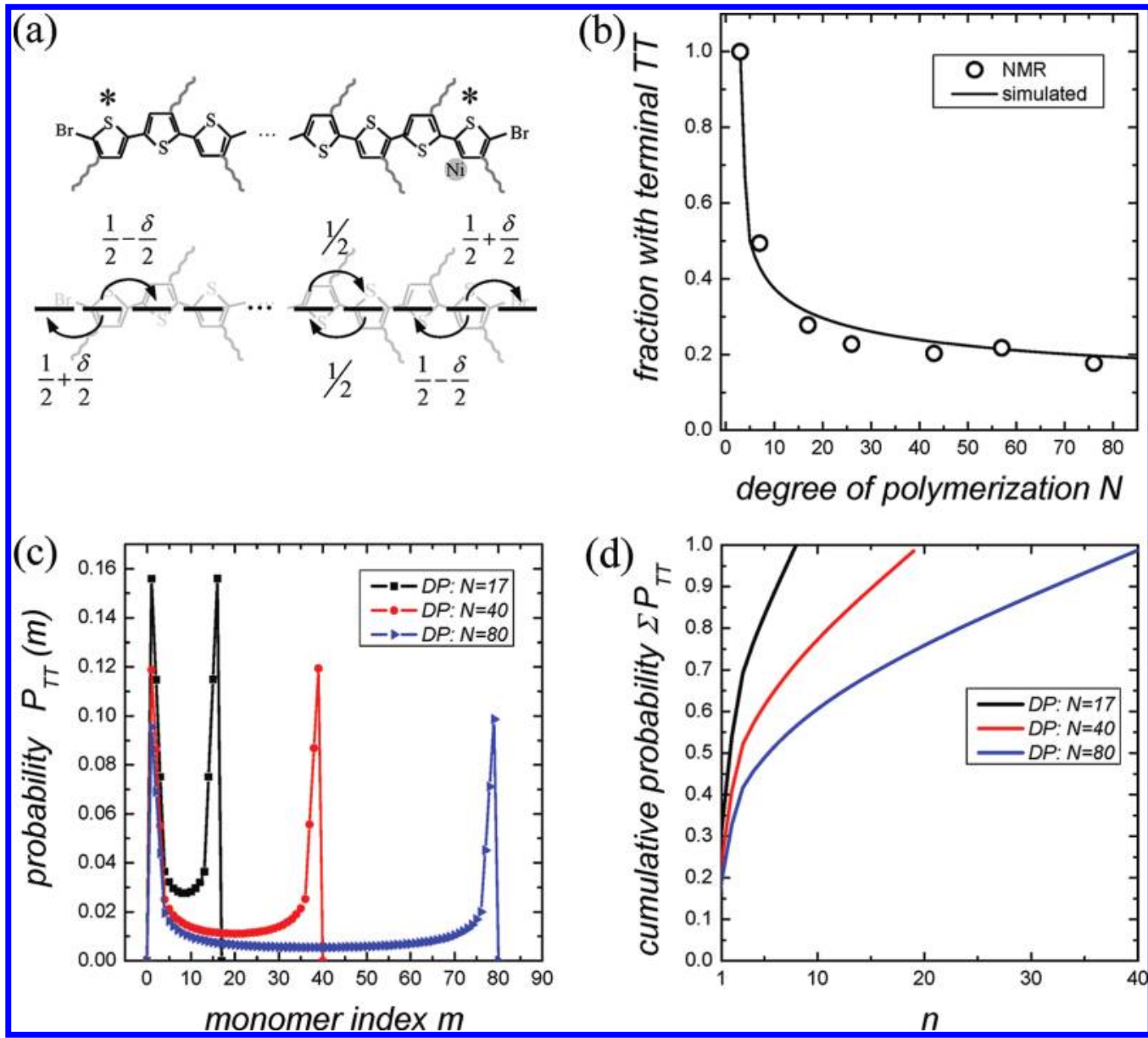

(d)

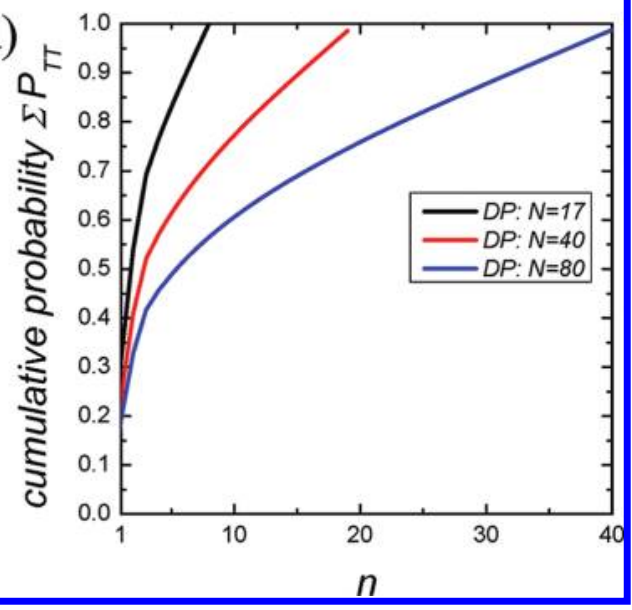

Figure 2. (a) Sketch explaining the "stickiness" parameter $\delta$ when $\mathrm{Ni}(0)$ is close to the chain ends (marked by *). (b) Probability of a terminal TT defect for $\mathrm{Ni}(\mathrm{dppp}) \mathrm{Cl}_{2}$-polymerized $\mathrm{P} 3 \mathrm{HT}$ as a function of molecular weight (circles) as determined from ${ }^{1} \mathrm{H}$ NMR. The first data point (trimer) is not from the experiment. The black line results from a simulation with stickiness $\delta=0.55$. (c) Probability $P_{\mathrm{TT}}(N, m)$ to find the TT defect at a certain monomer index $m$ for three different degrees of polymerization $\mathrm{N}$. (d) Cumulative probability to find the TT defect within the first monomer units $n$ from the end: $\sum P_{\mathrm{TT}}(N, n)=\sum_{i} 2 P_{\mathrm{TT}}(N, n)$ with $i=1, \ldots, n$. The factor 2 in the sum results from the symmetry of the distributions $P_{\mathrm{TT}}$.

DP (data not shown). For a given $\delta$, the model also gives the distributions of the TT defect along the chain. Figure $2 \mathrm{c}$ presents these distributions for $\delta=0.55$ for the three different degrees of polymerization, DP $=17,40$, and 80 . In all cases, the distributions are symmetric and the probability for chains with a terminal TT unit is highest, but most of the chains have an internal one. This is clearly illustrated by the cumulative probability $\sum P_{\mathrm{TT}}$ in Figure $2 \mathrm{~d}$ which gives the probability to find the TT defect within the first $n$ monomers from one of the chain ends.

\subsection{Synthesis of Defect-Free Poly(3-hexylthiophene).} Fully regioregular P3HT chains without any defects are synthesized via externally initiated KCTP. For this purpose, new soluble nickel initiators 3 with chelating phosphine ligands are prepared. 3a,b are synthesized from 2-bromo-3-hexylthiophene using diethylbipyridylnickel $\mathrm{Et}_{2} \mathrm{Ni}$ (bipy) following ligand exchange ${ }^{57,58}$ and isolated as golden-orange crystals (Scheme 1b, Scheme 2).

An alternative route toward initiators 3 starting from 2chloromagnesio-3-hexylthiophene and $\mathrm{Ni}(\mathrm{dppp}) \mathrm{Cl}_{2}$ is feasible and convenient for the in situ initiation of KCTP; ${ }^{59}$ however, we found that workup and purification was easier to handle using $\mathrm{NiEt}_{2}$ bipy. In contrast to conventional KCTP, in which two transmetalation steps with 2 equiv of active monomer molecules are required to generate $\mathrm{Ni}(0)$, complexes $\mathbf{3} \mathbf{a}, \mathbf{b}$
Scheme 2. Structures of Initiators $3 a$ and $3 b$ with Atom Numbering

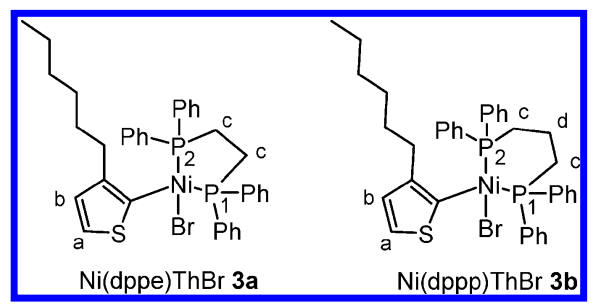

readily release $\mathrm{Ni}(0)$ after the first transmetalation and reductive elimination step. Defect-free P3HT $4 a-1$ was obtained by adding the active monomer to solutions of the initiator in THF, polymerizing for indicated times and quenching the mixture with $5 \mathrm{M} \mathrm{HCl}^{50} 3 \mathbf{a}$,b exhibit excellent solubility in THF, which facilitates precise adjustment of initiator to monomer ratio. Several batches with different initiator to monomer ratios were prepared to produce different molecular weights, and Soxhlet extraction was performed with methanol only. Thus, narrow polydispersities (GPC) as low as 1.11 were obtained using initiator $\mathbf{3 b}$ (see Table 1 , for GPC curves see Supporting Information). The polydispersity indices obtained from MALDI are shown as well; however, these are significantly smaller compared to the values from GPC. ${ }^{60}$ This 


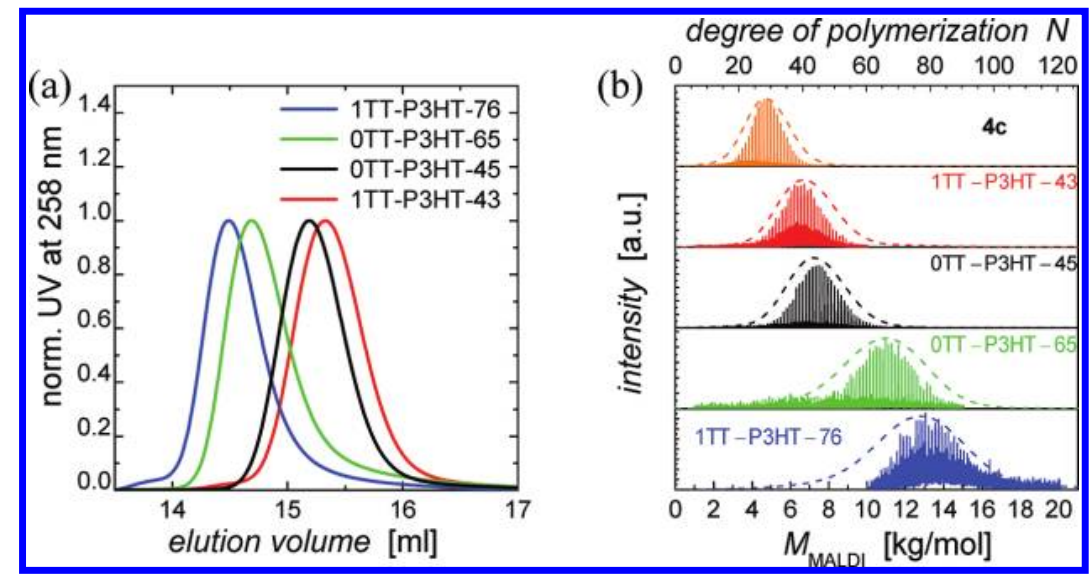

Figure 3. Molecular weights of the four samples studied in detail. (a) GPC curves measured in THF. (b) MALDI-ToF spectra. GPC curves are overlaid (dashed lines) by using the scaling $M_{\mathrm{MALDI}}=0.62 \mathrm{M}_{\mathrm{GPC}}$. In addition to the four samples in (a), the lower molecular weight sample 4c (0TT-P3HT-26, see Table SI-1) is shown.

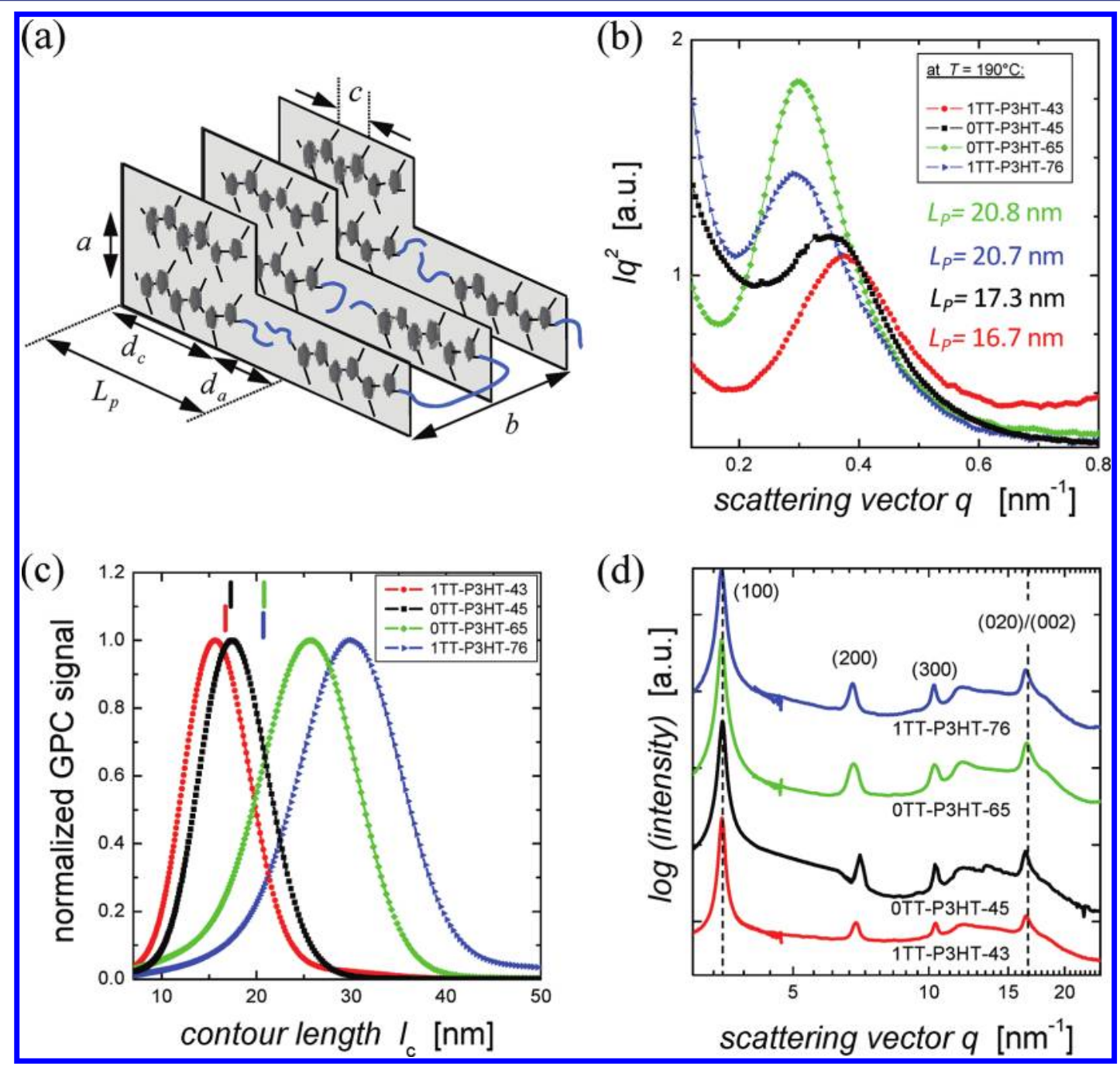

Figure 4. (a) Scheme of the semicrystalline microstructure of regioregular P3HT: $a, b$, and $c$ represent the crystal lattice constants; $d_{\mathrm{c}}$ and $d_{\mathrm{a}}$ are thicknesses of lamellar crystals and amorphous layers, respectively; $L_{\mathrm{p}}=d_{\mathrm{c}}+d_{\mathrm{a}}$ is the long period. (b) Lorentz-corrected small-angle X-ray scattering curves at $190{ }^{\circ} \mathrm{C}$ for the samples 1TT-P3HT-43 (red), 0TT-P3HT-45 (black), 0TT-P3HT-65 (green), and 1TT-P3HT-76 (blue). All samples were cooled from the melt in steps of $10 \mathrm{~K} . L_{\mathrm{p}}$ as obtained from the peak maximum are shown. (c) Contour length distributions obtained from Figure 3. Bars indicate $L_{\mathrm{p}}$ values as obtained from (b). (d) Wide-angle scattering curves of the four samples at $190{ }^{\circ} \mathrm{C}$.

common phenomenon is caused by the fact that higher molecular weights are lower in intensity in MALDI-ToF, which results in underestimated weight-average molecular weights and thus smaller PDI values. We will therefore use PDI values 


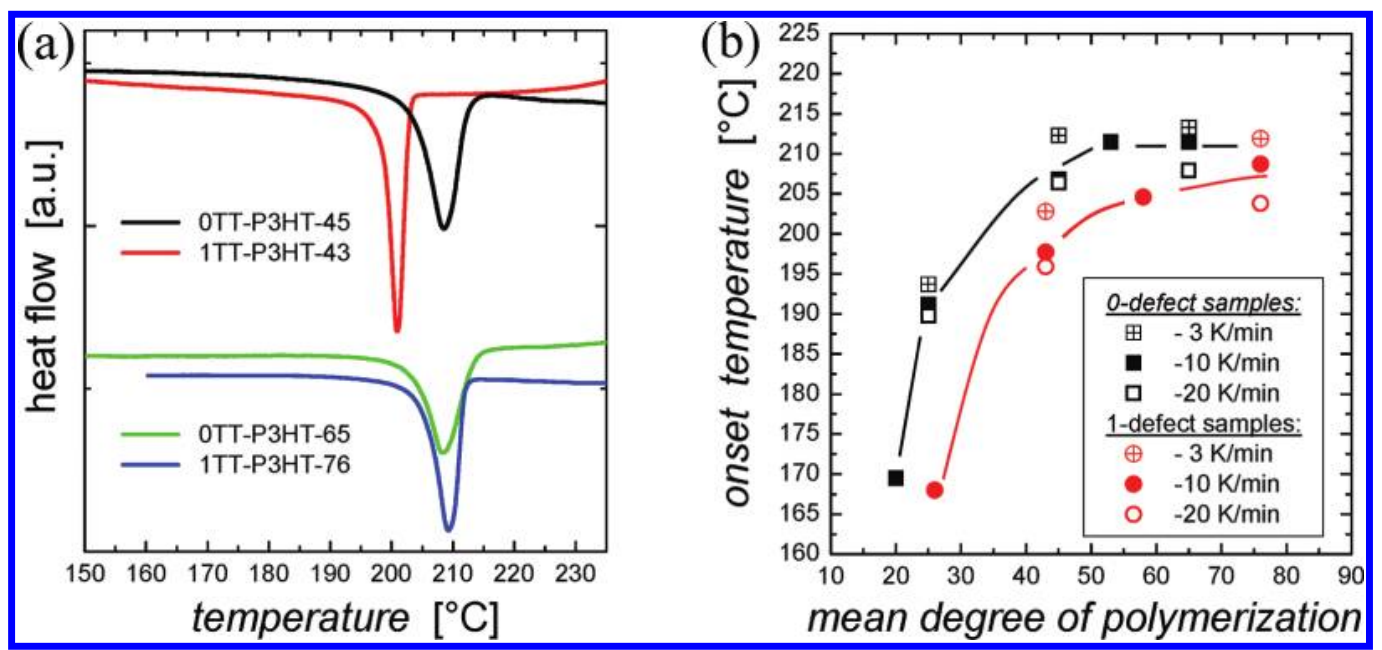

Figure 5. (a) Heat flow during cooling from the melt at a rate of $3 \mathrm{~K} / \mathrm{min}$. (b) Crystallization onset temperatures for a broader range of molecular weights and different cooling rates of $3 \mathrm{~K} / \mathrm{min}, 10 \mathrm{~K} / \mathrm{min}$, and $20 \mathrm{~K} / \mathrm{min}$. Lines are guides to the eye.

obtained from GPC and degrees of polymerization from NMR throughout this manuscript. Quantitative initiation efficiency of the initiator is verified by ${ }^{1} \mathrm{H}$ NMR spectroscopy (Figure $1 \mathrm{~b}$ ). In the spectrum of the fully regioregular chain $4 \mathbf{a}$, the two doublets of $\mathrm{H}_{11}$ and $\mathrm{H}_{12}$ are clearly seen at 7.16 and $6.93 \mathrm{ppm}$, respectively, in accordance with the literature. ${ }^{39,54,55,61}$ The fully regioregular structure is further corroborated by the fact that the signal of the HT-TT triad within the chain, as observed at $7.00 \mathrm{ppm}$ for conventionally initiated 2a (see arrow in Figure $1 \mathrm{a})$, is absent. While all defect-free polymers carry the 3hexylthiophene starting group, the situation concerning the nature of end-groups is slightly different. In principle, polymers with $\mathrm{H} / \mathrm{H}$ termination should be obtained, and this is indeed observed. With increasing molecular weight, however, the content of bromine-terminated P3HT chains increases slightly (see Figure SI-6, Supporting Information). We assume that bromine end groups arise from an irreversible loss of coordination of $\mathrm{Ni}(0)$ to the conjugated chain, the extent of which increases with increasing DP. The increasing amount of bromine terminated chains in $\mathbf{4 a}-\mathbf{f}$ is consistent with a slight but increasing low molecular weight tailing observed in the GPC curves (see Figure SI-5, Supporting Information). The noticeable intensity at the low molecular weight side, especially for the higher molecular weight polymers $4 \mathbf{e}, \mathbf{f}$ thus causes polydispersity indices (PDI) slightly higher than 1.2. This is not the case for polymers $4 \mathrm{~g}-\mathbf{l}$ initiated by the dppp-based initiator 3b. These polymers have comparable molecular weights but exhibit excellent PDIs down to 1.10 for the molecular weight region investigated. A full table with all relevant molecular parameters and physical properties is found in the Supporting Information (Table SI-1,2).

3.3. Influence of Polydispersity and Distributed Tailto-Tail Unit on Structure Formation. We select four polymers for an in-depth analysis in order to reveal the impact of the TT unit and polydispersity on structure formation and crystallinity. Samples $2 \mathrm{c}$ and $2 \mathrm{e}$ initiated with $\mathrm{Ni}(\mathrm{dppp}) \mathrm{Cl}_{2}$, denoted as 1TT-P3HT-43 and 1TT-P3HT-76, respectively, and the two defect-free samples $\mathbf{4 i}$ and $\mathbf{4 f}$, denoted as 0TTP3HT-45 and 0TT-P3HT-65, respectively, are analyzed by $\mathrm{X}$-ray scattering and various calorimetric experiments. "1TT" and "OTT" denote one and no TT defect, respectively, and the number at the end indicates the degree of polymerization. The samples synthesized via the same catalyst have different molecular weights, while the two molecular weights for each couple are similar. Note that polydispersities are almost equal for the two couples of comparable molecular weight. Table 1 summarizes all important parameters (for complete characterization, see Table SI-1,2). Figure 3a shows GPC curves, and Figure $3 b$ depicts MALDI ToF spectra. Temperature-dependent combined small-angle and wide-angle X-ray scattering experiments were performed on bulk samples to characterize the microstructure. Figure 4a schematically shows the semicrystalline morphology of $\mathrm{P} 3 \mathrm{HT}{ }^{46}$ Alternating crystalline and amorphous layers form a superstructure with periodicity $L_{\mathrm{P}}=$ $d_{c}+d_{a}$, where $L_{P}$ is the long period. Within the lamellar crystals, another layered structure is formed, comprising alkyl chain and thiophene main-chain "sheets" ( $a$-axis). The $\pi-\pi$ stacking of the planarized backbones is along the $b$-axis. Figure $4 \mathrm{~b}$ shows Lorentz-corrected small-angle X-ray (SAXS) intensities recorded at $T=190{ }^{\circ} \mathrm{C}$, i.e., a temperature close to the isothermal crystallization temperatures used in the DSC experiments below. The long periods $L_{\mathrm{P}}$ determined from the peak positions are indicated. The contour-length distributions shown in Figure $4 \mathrm{c}$ together with the $L_{\mathrm{P}}$ values have been calculated from GPC curves for which the molecular weight axis has been corrected by the MALDI spectra, i.e., the molecular weight axis of GPC data has been multiplied by a factor in order to have their maxima at the same positions as the MALDI spectra (Figure 3b). While samples 1TT-P3HT-43 and 0TT-P3HT-45 have a long period $L_{\mathrm{P}}$ very similar to its contour length $l_{\mathcal{c}}$ the higher molecular weight samples 0TTP3HT-65 and 1TT-P3HT-76 exhibit $L_{\mathrm{P}}$ values much smaller than $l_{c}$. From this we can conclude that 1TT-P3HT-43 and 0TT-P3HT-45 crystallize in an extended-chain conformation, while for 0TT-P3НT-65 and 1TT-P3HT-76, chain-folding occurs. Very similar positions of the (100)- and the (020)/ (002)-reflections in Figure $4 \mathrm{~d}$ indicate that the lattice parameters are independent of the presence or absence of the TT defect and are in accordance with the literature (Table 1). ${ }^{62,63}$

Figure 5a shows the DSC cooling curves of all four samples acquired at a rate of $3 \mathrm{~K} / \mathrm{min}$. Although the degree of polymerization of samples 0TT-P3HT-45 and 1TT-P3HT-43 is almost equal, cf., Table 1, the crystallization onset temperatures are significantly different. These values are shown in Figure $5 \mathrm{~b}$ as crossed symbols. Additionally, the onset temperatures 

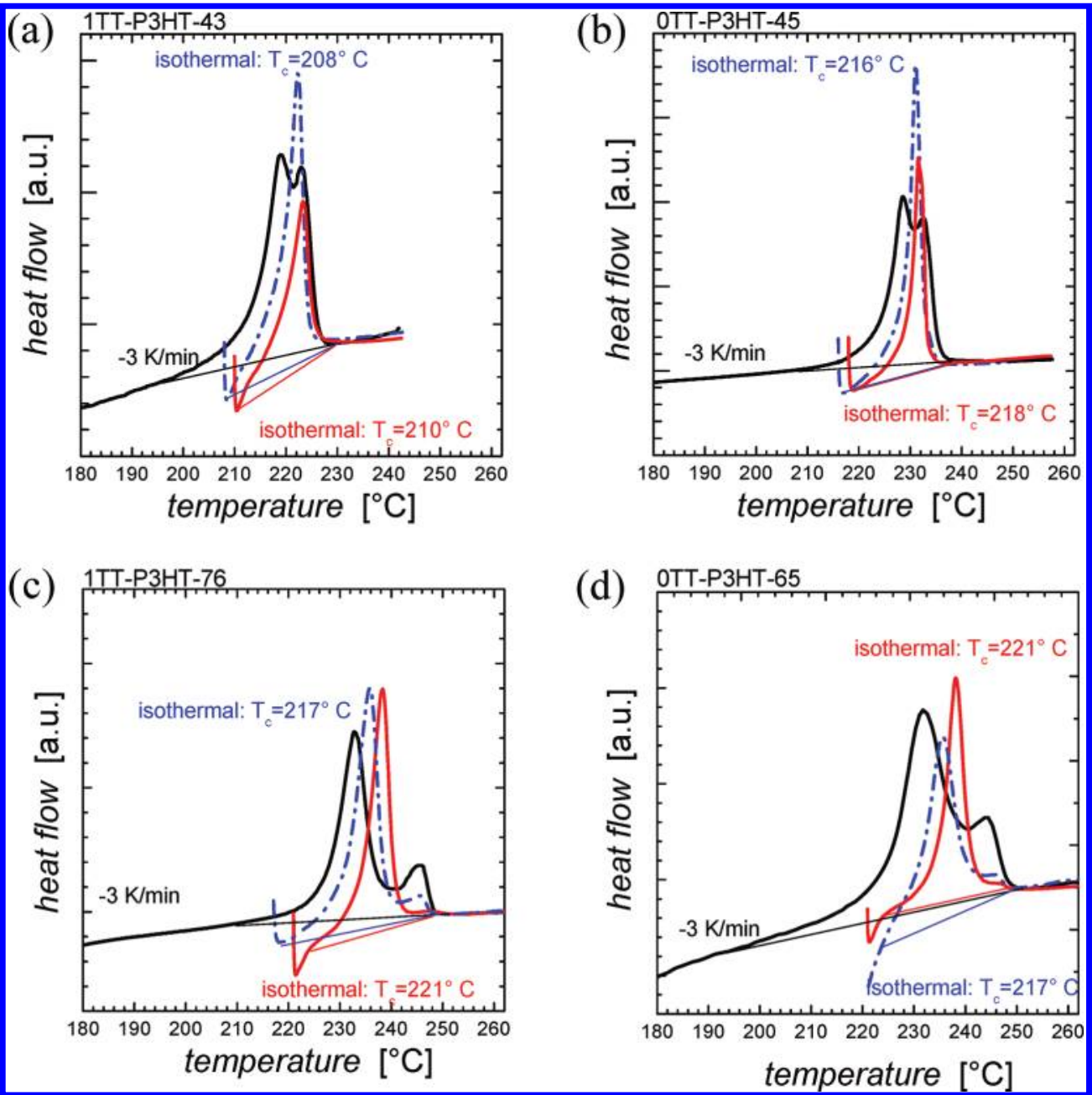

Figure 6. DSC heating curves at a rate of $20 \mathrm{~K} / \mathrm{min}$. For each sample, the heating curve after cooling at $3 \mathrm{~K} / \mathrm{min}$ (black line) is shown in addition to the heating curves after isothermal crystallization at the two highest temperatures (blue, red lines). (a) 1TT-P3HT-43, (b) 0TT-P3HT-45, (c) 1TTP3HT-76, and (d) 0TT-P3HT-65.

obtained from experiments performed with higher cooling rates and several molecular weights are shown. The onset temperatures depended on the cooling rate as expected, i.e., the higher the cooling rate, the lower the onset temperature. Furthermore, a clear difference between defect-free samples and samples containing one TT defect was observed at the same cooling rates. The P3HT samples with one TT defect crystallized at lower temperatures as compared to defect-free samples of similar degree of polymerization. This difference was more pronounced for lower molecular weights and seemed to vanish for the highest molecular weights studied. Calorimetric isothermal crystallization experiments at different temperatures were used to further explore the observed differences among the samples. Crystallization at higher temperatures requires thermodynamically more stable crystals, i.e., polymeric or oligomeric crystals with a larger thickness $d_{c}$ (cf., Figure 4a). Thus, size-limiting effects such as polydispersity or potentially noncrystallizable TT defects might become visible. Figure 6 shows the heating curves after isothermal crystallization at the two highest temperatures for each sample, in addition to the curve after nonisothermal crystallization during cooling at $3 \mathrm{~K} /$ min. For all samples, two peaks were observed during melting after cooling (black line). This is a well-known phenomenon, namely melting and immediate recrystallization or reorganiza- tion $^{64}$ into a thermodynamically more stable form. ${ }^{65}$ For the lower molecular weight samples 1TT-P3HT-43 and 0TTP3HT-45, heating after isothermal crystallization produced a single melting peak close to the higher melting peak of the nonisothermally crystallized samples. This peak shifted to higher temperatures with increasing crystallization temperature $T_{c}$. Furthermore, a reduction in the enthalpy of melting $\Delta H_{\mathrm{m}}$ with increasing $T_{c}$ was clearly seen. Also for the higher molecular weight samples 1TT-P3HT-76 and 0TT-P3HT-65, the dominant melting peak after isothermal crystallization shifted to higher temperatures with increasing $T_{\mathcal{O}}$ but here it was closer to the lower temperature melting peak of the nonisothermally crystallized case. Furthermore, also for the isothermally crystallized samples, the second melting peak at higher temperatures was still observable although significantly reduced in intensity. Because the results from small-angle X-ray scattering (Figure $3 \mathrm{~b}$ and $3 \mathrm{c}$ ) suggest partial chain folding for 0TT-P3HT-65 and 1TT-P3HT-76, we interpret the higher temperature melting peaks for these two samples as the melting of chains that recrystallized in an extended chain configuration.

The melting peak temperatures of all samples from Figure 6 are shown in Figure $7 \mathrm{a}$ as a function of $T_{\mathrm{c}}$. For all four samples, the increasing melting temperature with increasing $T_{\mathrm{c}}$ indicated an increased crystal thickness. Variations in melting points 

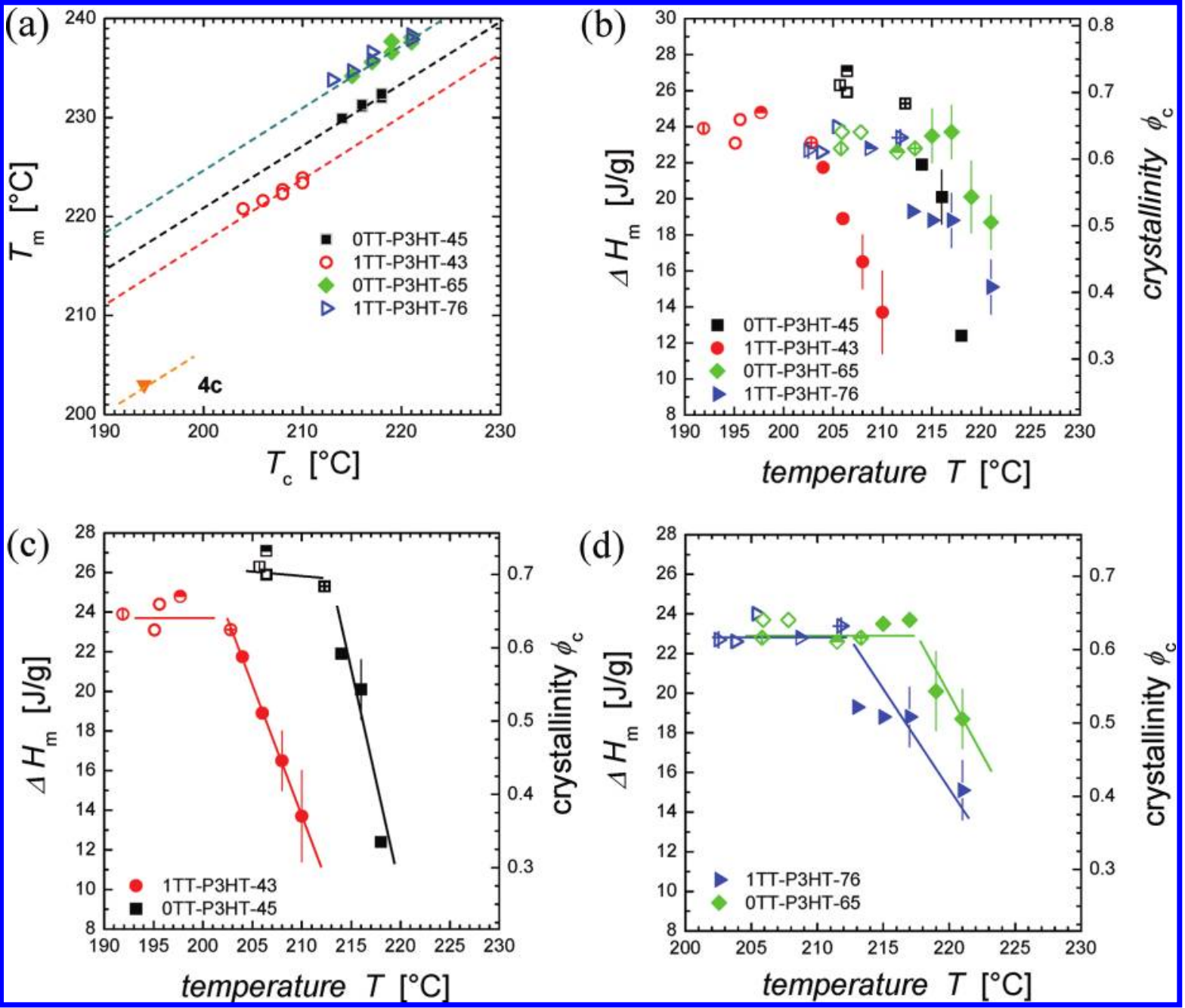

(d)

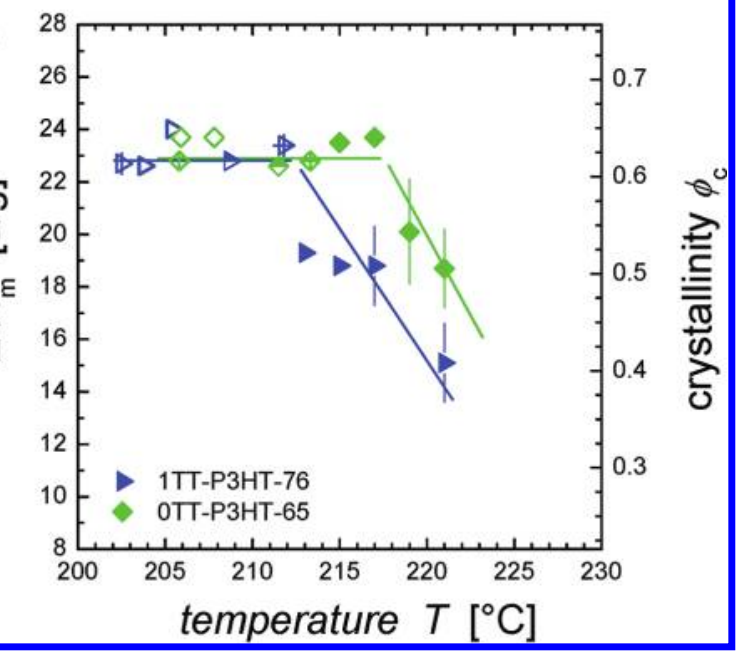

Figure 7. (a) Melting peak temperatures as a function of isothermal crystallization temperature (dashed lines guide the eyes). Additionally shown is the result of a nonisothermal experiment of the defect-free sample 0TT-P3HT-26 (4c, filled triangle). (b) Melting enthalpy after nonisothermal and isothermal crystallization (filled symbols): For nonisothermal crystallization $(-40 \mathrm{~K} / \mathrm{min}$ : symbols with vertical line; $-20 \mathrm{~K} / \mathrm{min}$ : open symbols, $-10 \mathrm{~K} / \mathrm{min}$ : half filled symbols; $-3 \mathrm{~K} / \mathrm{min}$ : symbols with cross) enthalpies are plotted as a function of the respective onset temperatures during cooling. The conversion of the melting enthalpy into crystallinity was performed by assuming $37 \mathrm{~J} / \mathrm{g}$ for a $100 \%$ crystalline sample. (c and d) Same data as in part b plotted separately for the two couples of lower and higher molecular weight. Lines guide the eyes.

among different samples are more difficult to interpret in terms of crystal thickness. For instance, Buckley et al. have shown for low molecular weight poly(ethylene oxide)s that once folded chain crystals melt at a temperature higher than that of extended chain crystals of chains having half the molecular weight. ${ }^{66}$ One reason for this effect is an entropic contribution from the chain ends. Such an entropic contribution was introduced by Flory and Vrij to describe the changes in melting points of monodisperse $n$-alkanes. ${ }^{67}$ It is therefore not evident that the different melting points of the samples in Figure $7 \mathrm{a}$ directly reflect variations in crystal thickness. Figure $7 \mathrm{a}$ additionally shows the melting point of the defect-free sample 0TT-P3HT-26 (4c) after cooling at $3 \mathrm{~K} / \mathrm{min}$ (filled triangle). The onset temperature during cooling was used as the crystallization temperature. This nonisothermal measurement together with the isothermal experiments for the other samples gives an impression on how the melting points change with molecular weight. It is apparent that it is not straightforward to relate the observed differences between 0TT-P3HT-45 and 1TT-P3HT-43 in Figure 7a to an effect of the TT defect. Figure $7 \mathrm{~b}$ shows $\Delta H_{\mathrm{m}}$ obtained from heating curves both after isothermal and nonisothermal crystallization. Figure $7 \mathrm{c}$ and $7 \mathrm{~d}$ show the same data for the lower and higher molecular weights separately for clarity. The values of $\Delta H_{\mathrm{m}}$ were converted into degrees of crystallinity $\phi_{\mathrm{c}}=\Delta H_{\mathrm{m}} / \Delta H_{\mathrm{m}}^{\infty}$ by using the recently suggested value of $\Delta H_{\mathrm{m}}^{\infty}=37 \mathrm{~J} / \mathrm{g}$ for the melting enthalpy of a $100 \%$ crystalline sample. ${ }^{68}$ The highest crystallinity of $\sim 70 \%$ is obtained for the defect-free sample 0TT-P3HT-45. This value is slightly higher compared to the counterpart with similar molecular weight 1TT-P3HT-43 having one TT defect, which exhibited $\sim 65 \%$. Higher values of $\Delta H_{\mathrm{m}}$ have only been reported recently on high pressure crystallized $\mathrm{P} 3 \mathrm{HT} .{ }^{37}$ It is important to note that irrespective of the presence or absence of a TT defect in the chain, a decrease in crystallinity is observed for all samples with increasing crystallization temperatures. For 0TT-P3HT-45, a sample without any potentially noncrystallizable regiodefects that forms extended chain crystals, polydispersity causes $\Delta H_{\mathrm{m}}$ to decrease for increasing $T_{\mathrm{c}}$ : with increasing temperature, crystals require longer chains in order to be stable, and thus an increasing amount of shorter chains is not able to crystallize. But for the other three samples, other reasons such as the presence of the TT defect or a 
reduction in the fraction of chains that fold might also apply. In order to be able to separate the contributions from polydispersity and the TT defect to crystallinity, a simple model is developed that allows estimation of the crystallinity.

3.4. Development of a Simple Model for the Determination of Crystallinity. The defect-free P3HT materials without any potentially noncrystallizable sequence allow development of a simple model. The model considers a solid solution of chains of different length, as justified by the observation of a single long period in Figure $4 \mathrm{~b}$. We further assume that the two repeat units at the chain end are noncrystalline and that no additional noncrystallizable sequences within the chains are present. For a given value of the crystal stem length $N_{\mathcal{c}}$ three different cases are possible for a chain with a degree of polymerization $N$ (Figure 8). First, the

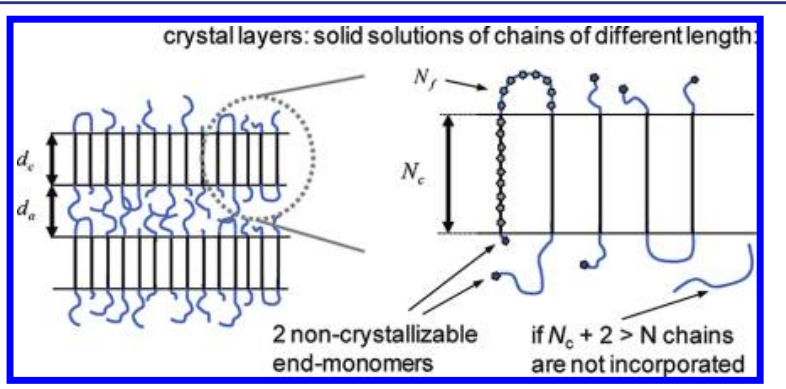

Figure 8. Scheme explaining the model for the determination of crystallinity: A solid solution of crystallizable chains of different length is assumed, i.e., crystallizable chains of different length are incorporated into the crystal layers at random positions. Chains ends (blue filled circles) were assumed to be noncrystalline. The minimum number of monomers necessary to form a fold is given by $N_{\mathrm{f}} N_{\mathrm{c}}$ denotes the crystal stem length, i.e., the thickness of the crystal layer, in units of monomers.

chain is long enough to fold and can therefore be incorporated into the crystal twice. In this case, $N \geq 2 N_{c}+2+N_{\mathrm{f}}$ has to hold, with $N_{\mathrm{f}}$ being the minimum number of monomers required per fold. Second, if the chain is not long enough to be incorporated twice, but can be incorporated once, $N \geq N_{\mathrm{c}}+2$ holds. Third, the chain is shorter than the crystal thickness, i.e., $N<N_{c}+2$. In this case, the chain is not incorporated into the crystal.

The crystallinity per chain for these three cases is then given by $2 N_{\mathrm{c}} / N, N_{\mathrm{c}} / N$, and 0 , respectively. To estimate the crystallinity of a particular sample for a given value of $N_{\mathcal{c}}$, the molecular weight distribution has to be taken into account to weight the three different cases correctly. The probability $p(N)$ to find a chain with degree of polymerization $N$ can be directly estimated from MALDI-ToF. Figure 9a shows the probabilities $p(N)$ for the three samples 0TT-P3HT-45, 1TT-P3HT-43, and 0TT-P3HT-65. The crystallinity $\varphi_{\mathrm{c}}\left(N_{\mathrm{c}}\right)$ was estimated according to:

$$
\phi_{\mathrm{c}}\left(N_{\mathrm{c}}\right)=\sum_{N \geq N_{\mathrm{c}}+2} p(N) \begin{cases}\frac{N_{\mathrm{c}}}{N}, & N<2 N_{\mathrm{c}}+2+N_{\mathrm{f}} \\ \frac{2 N_{\mathrm{c}}}{N}, & N \geq 2 N_{\mathrm{c}}+2+N_{\mathrm{f}}\end{cases}
$$

The model implicitly assumes a rejection of the chains ends from the crystal. This assumption may be justified by the observations that the long period of P3HT scales with molecular weight. ${ }^{34,46}$ Furthermore, the value chosen for $N_{f}$ also affects the calculated crystallinities. P3HT-folds in monolayers on graphite have been directly observed by scanning tunneling microscopy, ${ }^{69,70}$ whereby values of $N_{\mathrm{f}}=$ 6-8 were suggested, which are in accordance with theoretical models predicting short reentry. ${ }^{69,71}$ The observed lattice constant of $a=1.3 \mathrm{~nm}$ in these monolayers is smaller than the value of $a=1.6 \mathrm{~nm}$, which is commonly observed in bulk samples. This suggests that $N_{\mathrm{f}}$ in the bulk is somewhat larger. We therefore chose $N_{\mathrm{f}}=8$ for all calculations presented here (for the influence of $N_{\mathrm{f}}$ on the calculated crystallinities, see Figure SI-7a, Supporting Information). The presented model neglects all kinetic effects on structure formation but maximizes the crystallinity per chain under the assumption of a sharply defined crystal thickness.

The lines in Figure 9b depict the crystallinites $\phi_{c}\left(N_{c}\right)$ as obtained from the model for the two defect-free samples 0TTP3HT-45 and 0TT-P3HT-65. Both calculated crystallinities exhibit two maxima as a function of $N_{c}$. The origin of these two maxima can be understood as follows. For small values of $N_{\mathcal{c}}$ many chains are able to form a fold. With increasing $N_{\mathcal{O}}$ the crystalline fraction of these folded chain increases. With further increasing $N_{\mathcal{c}}$ the number of chains that are long enough to be incorporated into the crystal twice decreases. This leads to a first decrease in crystallinity (labeled " 1 " in Figure 9b). The second maximum again arises from an increase in the crystalline fraction per chain, which is now built into the crystal only once. Afterward the crystallinity decreases again ("2" in Figure 9b), because more and more chains are too short to crystallize at all, as their DP is smaller than the crystal stem length, i.e., $N<N_{c}+$ 2 . In both plots in Figure $9 \mathrm{~b}$, the maximum degree of crystallinity that is achievable is smaller in the first peak (second peak in Figure 9c and 9d), as chain-folding requires monomer units which are lost for crystallinity.

Figure 9c and 9d show the calculated crystallinities from Figure $9 \mathrm{~b}$ as a function of the inverse crystal stem length $N_{\mathrm{c}}^{-1}$ (gray lines). In addition, the experimentally determined values $\phi_{c}\left(T_{c}\right)$ are shown. For polymers with a high degree of polymerization, it is generally observed that the melting temperature of lamellar crystallites increases with increasing thickness. This effect is well described by the Gibbs-Thomson equation $T_{\mathrm{m}}=T_{0}-C N_{\mathrm{c}}^{-1}$. Here, $T_{0}$ is the equilibrium melting point, and the constant $C \sim 2 \sigma / \Delta H_{\mathrm{m}}^{\infty}$ is proportional to the surface energy $\sigma$ and the melting enthalpy $\Delta H_{\mathrm{m}}^{\infty}$ of a $100 \%$ crystalline sample. ${ }^{65}$ For the crystallization temperature and the crystal thickness, the same relation is often found. ${ }^{65}$ Although the above-mentioned entropic contributions from chain ends and differences in surface energies for extended and folded chain crystals modify the simple Gibbs-Thompson equation ${ }^{66}$ for oligomers, experimental data relating temperature and crystal thickness is usually presented in $T-N_{c}{ }^{-1}$ diagrams. As the higher melting points for the increased $T_{c}$ values in Figure $7 \mathrm{a}$ indicate larger crystal thicknesses, we plot the respective $x$ axis in Figure 9c and $9 \mathrm{~d}$ accordingly. The temperature range is chosen such that the decreasing DSC crystallinities can be superimposed with the decrease in the calculated crystallinities. Because 0TT-P3HT-45 exhibits extended-chain crystals, the experimentally determined crystallinities are superimposed with the second decrease of the calculated ones (" 2 " in Figure 9b). For 0TT-P3HT-65, the comparison of the long period and the chain length indicates chain-folded crystals, and therefore the experimentally determined crystallinities are superimposed with the first decrease of the calculated curve (" 1 " in Figure 9b). 

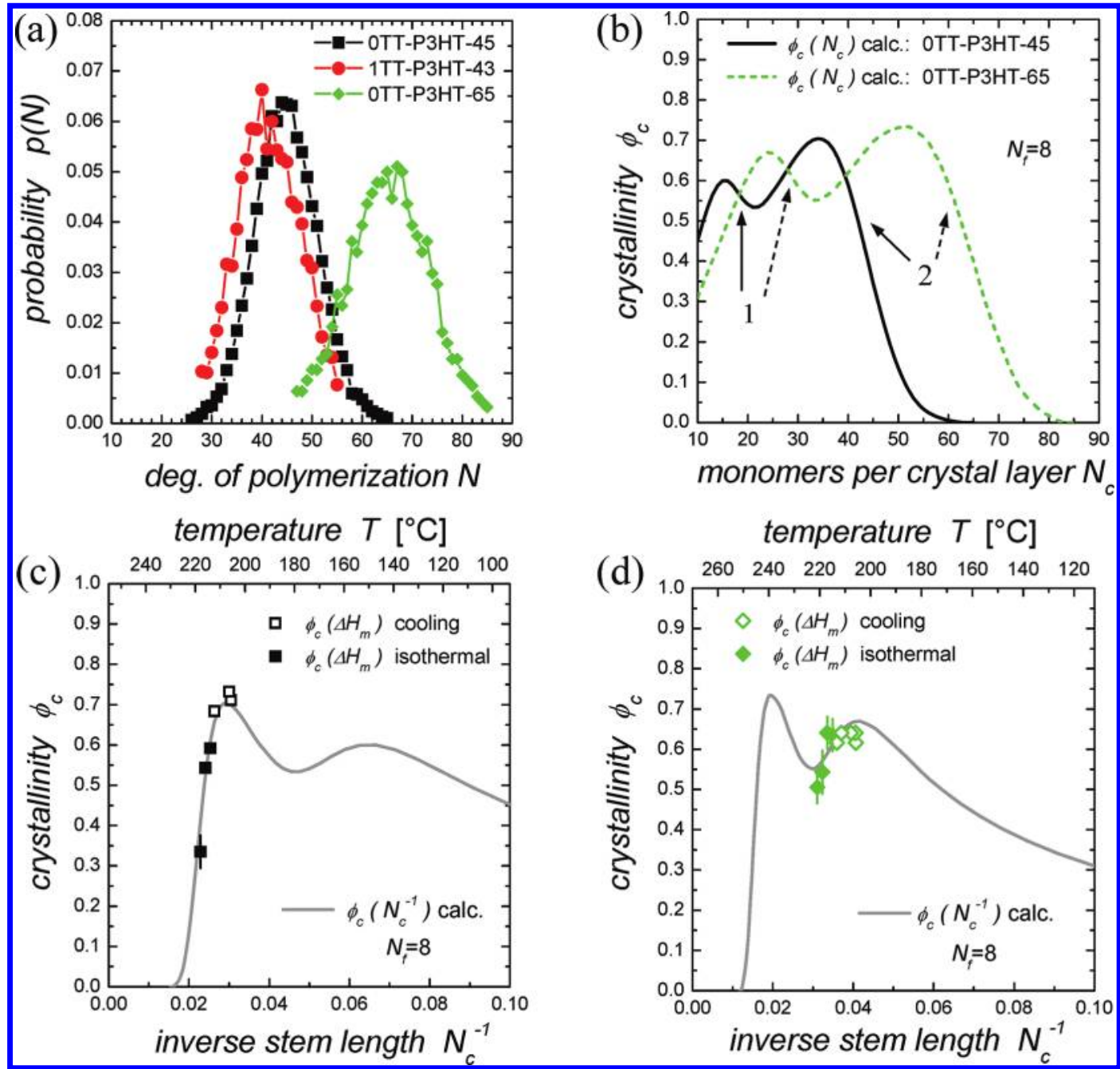

Figure 9. (a) Distributions of degree of polymerization $N$ from MALDI spectra for the different samples as indicated. (b) Crystallinities calculated with eq 1 for the two samples 0TT-P3HT-45 and 0TT-P3HT-65. The arrows labeled "1" and "2" indicated the first and second decrease in both crystallinity curves, respectively, with increasing crystal thickness. (c) Calculated crystallinity (gray line) with $p(N)$ of 0 TT-P3HT-45 as a function of the inverse crystal thickness. The squares are crystallinity values obtained from the melting enthalpies. As indicated by SAXS, samples in this molecular weight range form extended chain crystals. The temperature axis is therefore plotted such that the decrease in DSC crystallinities superimposes with the second decrease of the calculated crystallinity (" 2 " in b). Note that the crystallinity axis has not been adjusted. (d) Same plot as $\mathrm{c}$ for 0TT-P3HT-65. As SAXS indicates once folded chains, the temperature axis is plotted such that the decrease in DSC crystallinities superimposes with the first decrease in the calculated crystallinity (" 1 " in b).

Both cases yield very good agreement of calculated and experimentally determined values. The model also reproduces the observed slightly lower crystallinity of 0TT-P3HT-65 compared to 0TT-P3HT-45. In addition, the shape of the experimental data and the calculated curves match well. All this demonstrates that the very simple model presented here accounts for the major experimental observations. It also indirectly supports the recently suggested value $\Delta H_{\mathrm{m}}^{\infty}=37 \mathrm{~J} / \mathrm{g}$ for a $100 \%$ crystalline sample, ${ }^{68}$ as compared to the previously used value $\Delta H_{\mathrm{m}}^{\infty}=99 \mathrm{~J} / \mathrm{g}$. ${ }^{72}$ Importantly, the model reveals that the reasons for the decrease in crystallinity with increasing isothermal crystallization temperature for 0TT-P3HT-45 and 0TT-P3HT-65 are indeed different: While the decreasing crystallinity in 0TT-P3HT-45 is caused by the increasing fraction of chains that are too short to crystallize at all, the decrease in crystallinity of 0TT-P3HT-65 arises from chains that are too short to be incorporated into the crystal twice.
The very good agreement of model and experiment emphasizes the major importance of polydispersity as a limiting factor for crystallinity. Although the crystallinity of 0TT-P3HT45 is rather high, it is essentially limited by polydispersity. Our model predicts that a reduction in polydispersity should lead to significantly higher crystallinites. For example, a reduction of the number of different chain lengths to $\sim 10$ (corresponding to a $\mathrm{PDI}_{\mathrm{MALDI}}$ of 1.002) is expected to result in crystallinities as high as $\phi_{\mathrm{c}}\left(N_{\mathrm{c}}\right) \approx 0.85$ (see Figure SI-7). This is valid for extendedchain crystals as well as for once-folded ones; however for the latter, crystallinity is additionally reduced by the fold.

In order to calculate crystallinities of P3HT samples synthesized via $\mathrm{Ni}(\mathrm{dppp}) \mathrm{Cl}_{2}$ and to address the question of whether the TT defect disrupts the crystallizable segment length thereby limiting crystallinity or not, the simulated distribution of the TT defect is finally considered in the model. The equilibrium theory of Flory ${ }^{73}$ assumes complete exclusion of defects; however, other theories and experiments suggest 


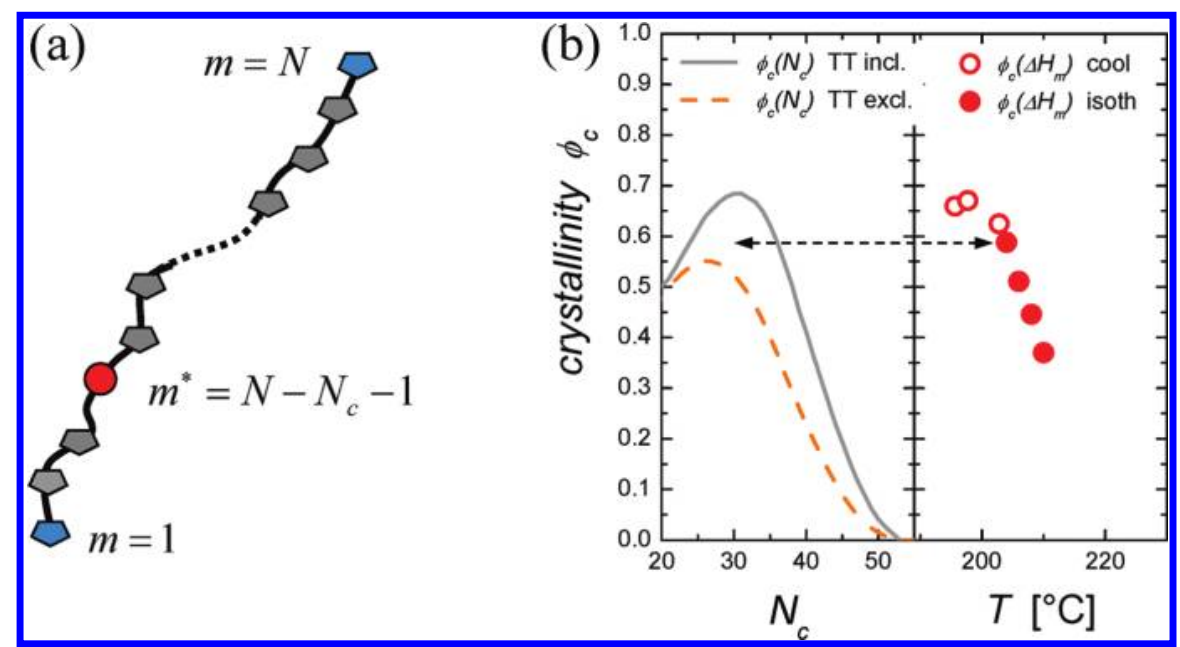

Figure 10. (a) Sketch of a P3HT chain with a degree of polymerization of $N$ that contains a TT defect (red circle). (b) 1TT-P3HT-43. Left: Crystallinity as a function of the crystal thickness calculated considering the TT defect as crystallizable (eq 1, gray line) or as noncrystallizable (eq 2, dashed orange line). Right: Crystallinity values as obtained from nonisothermal (open circles) and isothermal (filled circles) DSC experiments.

partial inclusion. ${ }^{74,75}$ Inclusion or exclusion is expected to depend on the exact nature or the size of the defect, ${ }^{76}$ because the crystal lattice is disturbed upon inclusion. In addition, molecular weight may play a role, too. On the one hand, Ungar and co-workers found that in crystals composed of ethylene oligomers with one single methyl branch, the comonomer was rejected from the crystal. ${ }^{77,78}$ On the other hand, experiments on higher molecular weight ethylene-propylene copolymers have shown that $\sim 7$ propylene units per 100 units can be incorporated into the crystal, which is accompanied by an increase in the unit cell dimensions. ${ }^{77,79}$ The crystal structure of P3HT with its alternating thiophene and alkyl layers in one direction, cf., Figure 4a, is rather peculiar, as the alkyl chains are often amorphous (in the molecular weight range studied here ${ }^{46}$ ) and the 'crystal' thus contains disordered regions. The fact that regiorandom-P3HT, which contains many $\mathrm{HH}$ and TT-coupling defects, does not crystallize at all, already demonstrates the detrimental effect that regiodefects can have on crystallinity. Wu et al. reported that regioregular poly(3-butylthiophene-ran-3-octylthiophene), i.e., a thiophene backbone to which alkyl chains of different length are attached in a random order, is still able to crystallize. ${ }^{80}$ This indicates that a certain irregularity with respect to side-chain order might be tolerated.

To investigate the behavior of the single TT defect in P3HT, complete exclusion from the crystal is assumed first. Here only extended chain crystals are considered. If the TT defect cannot be incorporated into the crystal, it divides the chain into two parts, cf., Figure 10a. If for the degree of polymerization $N>$ $2 N_{c}+2$ holds, at least one of those two parts will be longer than $N_{\mathcal{O}}$ independent of the location of the TT defect. If $N \leq$ $2 N_{c}+2$, the TT defect has to be located within the first $m^{*}$ monomers from either chain end, cf. Figure 10a, for the chain to be able to crystallize with a crystal stem length of $N_{c}$. Otherwise, both chain segments are shorter than $N_{c}$ and the chain will not crystallize at all. The cumulative probability $\sum P_{\mathrm{TT}}\left(N, m^{*}\right)$ (cf. Figure $2 \mathrm{c}$ ) gives the fraction of chains with degree of polymerization $N$ that have the TT defect within the first $m^{*}$-monomers from either chain end. Thus, the crystallinity can be estimated within the model for extended chain crystals by calculating

$$
\begin{aligned}
\phi_{\mathrm{c}}\left(N_{\mathrm{c}}\right)= & \sum_{N \geq N_{\mathrm{c}}+2} p(N) \frac{N_{\mathrm{c}}}{N} \\
& \left\{\begin{array}{cc}
1, & N>2 n_{\mathrm{c}}+2 \\
\sum P_{\mathrm{TT}}\left(N ; N-N_{c}-1\right), & N \leq 2 n_{\mathrm{c}}+2
\end{array}\right.
\end{aligned}
$$

Note that here only extended chain crystals were considered, and therefore an uncertainty in the choice of the parameter $N_{\mathrm{f}}$ did not play a role. From this extended model, the crystallinity expected for 1TT-P3HT-43 is shown in Figure $10 \mathrm{~b}$ as the dashed line. For comparison, the crystallinity calculated with eq 1, i.e., assuming complete inclusion of the TT defect, is shown as a solid line. The crystallinity obtained from the isothermal DSC experiment at the lowest isothermal crystallization temperature $T_{\mathrm{c}}=204{ }^{\circ} \mathrm{C}$ is $\phi_{\mathrm{c}}\left(\Delta H_{\mathrm{m}}\right)=0.59$. The calculated crystallinities for complete exclusion of the TT defects are lower than this value over the whole range of $N_{c}$ (see arrow in Figure 10b).

Thus, for complete exclusion, the predicted reduction in crystallinity is too large, which in turn indicates that partial inclusion of the TT defects occurs. Reassessing the thermal properties discussed in Figure $5 b$, we can now view the smaller onset temperatures of crystallization of samples with one TT unit as an increase in the free energy of the crystal. Complete inclusion of the TT defect, however, seems unlikely for the following reason: The decreasing crystallinity of 0TT-P3HT-65 with increasing $T_{c}$ (Figure $7 \mathrm{~d}$ ) was caused by the increasing fraction of chains that were too short to be incorporated into the crystal twice. One would expect that such a decrease occurs only at higher temperatures for the higher molecular weight sample 1TT-P3HT-76, if the TT defect could be included completely. However, as can be seen from Figure $7 \mathrm{~d}$, the crystallinity starts to decrease at lower temperatures for 1TTP3HT-76 as compared to 0TT-P3HT-65. This is consistent with a partial exclusion of the TT unit, and therefore complete inclusion is unlikely.

Several reports have mentioned that head-to-head $(\mathrm{HH})$ units do affect crystallinity, ${ }^{28,39,81,82}$ although a quantitative 


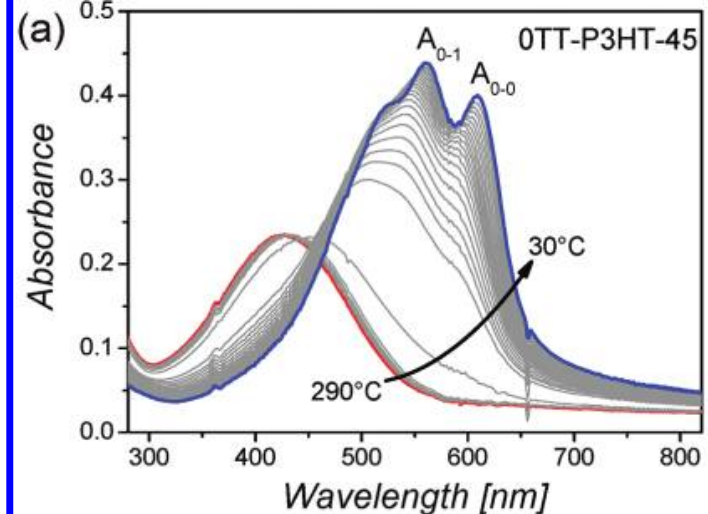

(c)

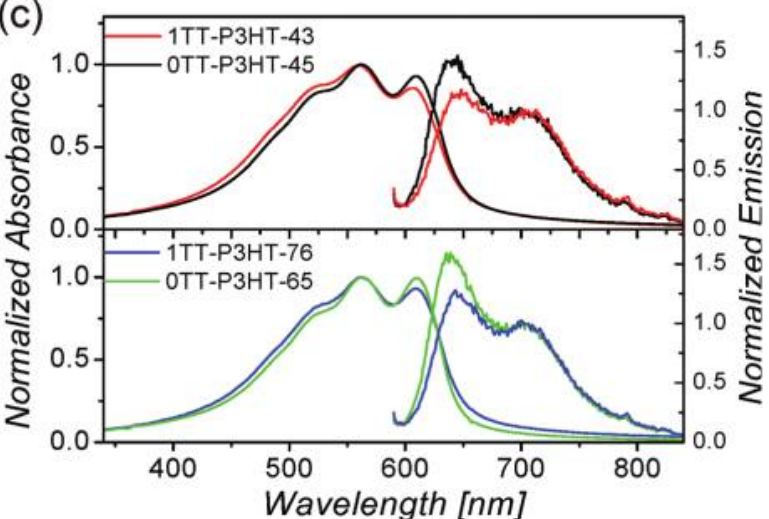

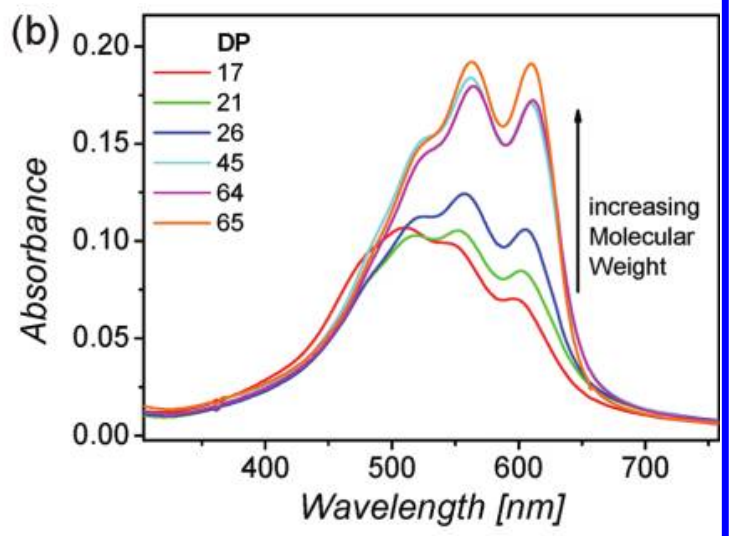

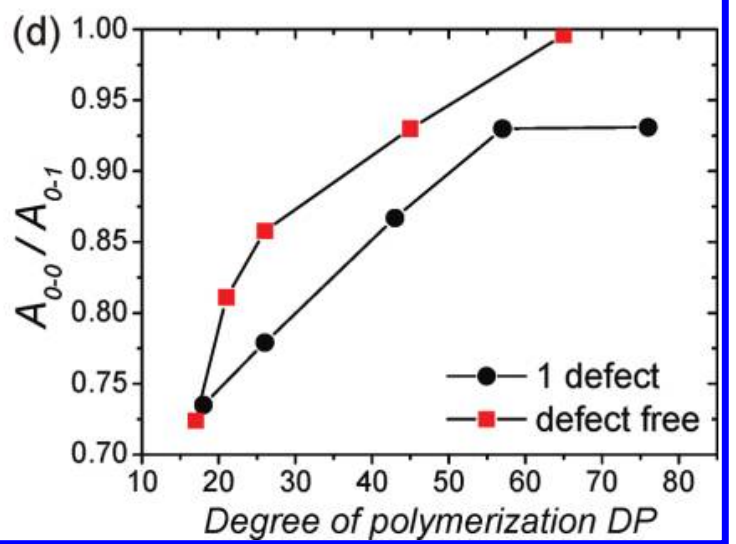

Figure 11. (a) Temperature-dependent absorption spectra of a 0TT-P3HT-45 film, measured in steps of $10 \mathrm{~K}$. (b) Absorption spectra of 0TT P3HT with different molecular weights. (c) Comparison of absorption and emission of 0TT-P3HT-45 and 1TT-P3HT-43 (upper graph) and 0TT-P3HT65 and 1TT-P3HT-76 (lower graph). (d) Peak ratio of the first $\left(\mathrm{A}_{0-0}\right)$ and second $\left(\mathrm{A}_{0-1}\right)$ vibronic progression in absorption.

study has not yet been presented. In a very recent report, Snyder et al. have observed a decrease of crystal thickness with decreasing RR, which the authors ascribed to noncrystallizable $\mathrm{HH}$ defects that limit the crystallizable segment length. ${ }^{38}$ Here it is interesting to note that the crystal lattice of P3HT can partially tolerate inclusion of the TT defect. Obviously structure formation is more severely affected by $\mathrm{HH}$ defects. Indeed, it is a reasonable assumption that planarity of the backbone is less severely distorted by single TT units, whereas $\mathrm{HH}$ couplings cause a stronger torsion of the backbone, either through sulfur-alkyl chain or alkyl chain-alkyl chain interactions. ${ }^{54}$ Therefore, the degree of crystallinity of $\mathrm{Ni}(\mathrm{dppp}) \mathrm{Cl}_{2}$-initiated samples is only reduced slightly when compared to the defectfree samples (see Figure 7c).

Finally, it is noteworthy to comment on the utility of the presented model for other samples in the literature prepared via $\mathrm{Ni}(\mathrm{dppp}) \mathrm{Cl}_{2}$. This is a feasible task, provided that high quality MALDI-ToF spectra are available from polymers that form extended-chain crystals. If higher molecular weights and/or broad polydispersities are to be simulated, complication arises from the fact that multiple chain-folding becomes possible. The herein presented model is entirely based on thermodynamic considerations, and we have only treated extended-chain and once-folded crystals. Structure formation of P3HT with higher molecular weight and broader PDI can be influenced by kinetic effects, leading to multiple chain-folding, and a detailed study is necessary to explore to what extent the presented model can be applied. There is no intrinsic limitation of the model itself; however, one must note that for these reasons, no model predicting crystallinity for high molecular weight polymers is available at present. To check the validity of the model for higher molecular weights and larger polydispersities, various cases that allow for twice or more folded chains need to be introduced in eq 1 for 0TT-P3HT and in eq 2 for 1TT-P3HT.

3.5. Optical Properties. Our model and the results from calorimetry both suggest that partial incorporation of the TT defect takes place in conventionally polymerized P3HT. Keeping in mind that backbone torsion for TT units is likely to be smaller in comparison with $\mathrm{HH}$ defects, ${ }^{54}$ and that the overall degree of crystallinity of 1TT-P3HT-43 is only reduced slightly compared to 0TT-P3HT-45, the effect of a single TT unit on the optical properties appears particularly interesting. Figure 11a shows the absorbance spectra of a 0TT-P3HT-45 film cooled from the melt $\left(T=290^{\circ} \mathrm{C}\right)$ to room temperature. The large disorder in the melt causes only one broad absorption feature at around $450 \mathrm{~nm}$, which is comparable to its solution spectrum or that of regiorandom amorphous P3HT. Upon crystallization, the polymer chains undergo conformational changes and spacial rearrangements that affect the respective coupling within and among the conjugated polymer chains. ${ }^{83}$ On the one hand, the planarization of the polymer backbone leads to a broad exciton intrachain delocalization, and on the other hand, the cofacial alignment in the $\pi-\pi$ stacking direction leads to an interchain coupling. The typical resulting absorption spectrum consists of several distinct vibronic progressions with a spacing of around $0.18 \mathrm{eV}$ appearing between 480 and $620 \mathrm{~nm}$. Spano explained these observations by considering weakly coupled $\mathrm{H}$-aggregates with a strong exciton-phonon coupling. He calculated the transition probabilities of the different vibronic bands from the ground 
state (GS) to an excited state (ES) depending on the disorder within the aggregates. ${ }^{84}$ Recrystallization of P3HT-0TT-45 starts from $250{ }^{\circ} \mathrm{C}$ and lower (Figure 11a). With higher crystallinity, the blue shoulder decreases and the ratio between first and second vibronic level increases, showing increased ordering. Interestingly, at temperatures below $T_{\mathrm{c}}$ and even below $60{ }^{\circ} \mathrm{C}$, where no more macroscopic structural changes take place, further changes are still visible in the optical spectra. We found these changes to be reversible and there seems to be a clear temperature dependence for the exciton delocalization. These temperature-dependent changes especially have to be taken into account when performing, for example, timeresolved pump probe laser spectroscopy, where the pump laser may heat the sample locally and modulate the spectra. ${ }^{85}$ The peak ratio of the first and second vibronic transition $\mathrm{A}_{0-0} / \mathrm{A}_{1-0}$ can be directly related to the strength of interchain coupling which again relates to the order and planarization within $\mathrm{H}$-aggregates. ${ }^{86}$ We will show later, together with the photoluminescence of these samples, that this model of pure $\mathrm{H}$-aggregates may not be simply applicable here. Still, the ratio $\mathrm{A}_{0-0} / \mathrm{A}_{1-0}$ directly correlates to the disorder in these polymer aggregates. ${ }^{84}$ In the following we plot this ratio which provides a simple way to compare all samples regarding their innercrystalline planarity, i.e., the average conjugation length. Figure $11 \mathrm{~b}$ and $11 \mathrm{~d}$ demonstrates how $\mathrm{A}_{0-0} / \mathrm{A}_{1-0}$ increases with molecular weight for defect-free P3HT, which can be explained by the increasing conjugation length within chain-extended crystals of increasing thickness. $A_{0-0} / A_{1-0}$ approaches unity for the highest molecular weight sample 0TT-P3HT-65.

In principle the TT defect can affect the conjugation length in two ways: In the case of complete exclusion, a reduction of the crystallizable sequence length results in thinner crystals and consequently in a shorter effective conjugation length, concomitant with a higher amorphous contribution to the spectra compared to a defect-free sample of identical molecular weight. In the case of partial inclusion of the TT defect, a reduction in the planarity of the backbone is likely. This can limit the conjugation length as well. The comparison of $\mathrm{A}_{0-0}$ / $\mathrm{A}_{1-0}$ ratios of 1TT-P3HT and 0TT-P3HT materials is shown in Figure $11 \mathrm{c}$ and $11 \mathrm{~d}$. In both cases, $A_{0-0} / A_{1-0}$ increases with molecular weight up to $\mathrm{DP} \approx 60$, but there is a clear difference between $0 \mathrm{TT}$ and $1 \mathrm{TT}$ polymers. The 0TT polymers always exhibit the higher ratio. The amorphous contribution is, however, nearly the same for both (Figure 11c). Higher molecular weights result in thicker crystals and thus in an increased conjugation length, while at a given molecular weight the defect-free samples provide more planar and "kink-free" chains. Both effects increase the exciton delocalization per chain, i.e., the average effective conjugation length. The higher ratios $\mathrm{A}_{0-0} / \mathrm{A}_{0-1}$ for defect-free P3HT chains (Figure 11d) therefore mirror the higher crystallization temperatures (Figure $5 b)$. Further support for the interpretation that the effective conjugation length within the crystal here is strongly influenced by the inclusion of TT defects comes from the comparison of the degrees of polymerization at equal ratios $A_{0-0} / A_{0-1}$. For instance, in order to achieve a value of $\mathrm{A}_{0-0} / \mathrm{A}_{0-1}=0.85$, the DP of the 1TT samples have to be nearly twice as high as in the case of 0TT samples. If only the crystal stem length was determining the effective conjugation length, this would imply that the 1TT samples are less crystalline than 0TT samples by a factor of $\sim 2$ for an identical DP. This is not consistent with the calorimetric results. Thus, the optical data support the picture of partial inclusion of TT defects and are fully congruent with the calorimetric data and the calculated crystallinities.

Also photoluminescence (PL) has significant features that relate to backbone planarization and formation of either $\mathrm{J}$ - or $\mathrm{H}$-aggregates. $\mathrm{H}$-Aggregates have a distinct emission spectra, as their lowest vibronic transition is forbidden. ${ }^{87}$ Previously, it has been shown by temperature-dependent solution measurements that the first vibronic peak in the emission spectra of P3HT decreases with increasing aggregation. ${ }^{88}$ In contrast, Figure $11 \mathrm{c}$ shows that the PL intensity of the $\mathrm{E}_{0-0}$ peak is very pronounced. This $E_{0-0}$ peak even exceeds the strength of the $E_{1-0}$ peak, which has not been observed previously for P3HT samples with high regioregularity. ${ }^{88}$ This observation is even more pronounced for the defect-free samples. The absorption spectra coincide with a higher order of the polymer chains, but the strong $\mathrm{E}_{0-0}$ emission cannot be explained by only assuming $\mathrm{H}$-aggregates. The increase of the $\mathrm{E}_{0-0}$ emission would substantiate the picture of a more delocalized exciton on the polymer chain experiencing a higher conjugation length, thereby reducing the coupling between neighboring chains. ${ }^{89}$ Thus, the defectfree samples exhibit a clear trend toward longer conjugation lengths and more planar backbones, which again is in accordance with partially incorporated TT units in conventionally polymerized chains.

\section{CONCLUSIONS}

By combining directed synthesis, structure analysis, and simulations, we have presented an integrated approach to systematically elucidate the influence of single molecular parameters on structure formation and optical properties in semicrystalline poly(3-hexylthiophene). Our results show that conventionally synthesized $\mathrm{P} 3 \mathrm{HT}$ using $\mathrm{Ni}(\mathrm{dppp}) \mathrm{Cl}_{2}$ as the catalyst not only contains terminal tail-to-tail defects as believed to date but also internal ones. The statistical distribution of this defect within the chain was quantified based on NMR end group analysis and simulations. Well-defined, narrow-distributed, defect-free P3HT with a regioregularity of $100 \%$ was prepared via externally initiated KCTP using new, soluble nickel initiators. The thermal behavior and the optical properties of the two series of P3HTs, i.e., well-defined P3HT chains with one distributed tail-to-tail defect obtained from the conventional initiation via $\mathrm{Ni}(\mathrm{dppp}) \mathrm{Cl}_{2}$ and welldefined, entirely defect-free P3HT via new nickel initiators, were distinctively different. The absence of any potentially noncrystallizable regiodefect allowed us to propose a simple model to estimate crystallinities based on the molecular weight distribution only. Ample viability of this model is demonstrated by the very good agreement of experimentally determined and calculated crystallinities. Importantly, polydispersity is identified as a major parameter determining crystallinity. Assynthesized defect-free materials exhibit crystallinities as high as $\sim 70 \%$, which can further be increased by lowering polydispersity. The combination of the results on the defectfree chains, the proposed model, and the distributions of the regiodefect within $\mathrm{Ni}(\mathrm{dppp}) \mathrm{Cl}_{2}$-initiated $\mathrm{P} 3 \mathrm{HT}$ strongly indicate that the tail-to-tail unit is at least partially included into the crystal layers. This result is fully supported by optical properties, where a high planarity of the backbone is indicated by the strong increase of the first vibronic absorption peak $\mathrm{A}_{0-0}$ compared to the second $\mathrm{A}_{0-1}$. At the same time, the higher order seems to augment exciton delocalization and to weaken $\mathrm{H}$-aggregate behavior, which is currently under a more detailed investigation. Complementary measurements of charge carrier 
mobility in film and bulk as well as of exciton diffusion lengths are now needed in order to relate these results to electronic properties as the next step, and these are currently underway. Because the presented approach is not limited to P3HT, it is our hope that it may find application in fundamental studies on the optoelectronic properties of other conjugated polymers with semicrystalline morphology, especially where polydispersity can be lowered by employing chain-growth polymerizations instead of traditional step-growth polycondensations. $5,41,90,91$

\section{ASSOCIATED CONTENT}

\section{S Supporting Information}

Instrumentation, NMR spectra and additional assignments, GPC curves, tables with full physical properties, and additional simulations. This material is available free of charge via the Internet at http://pubs.acs.org.

\section{AUTHOR INFORMATION}

\section{Corresponding Author}

michael.sommer@makro.uni-freiburg.de

\section{Present Address}

${ }^{\#}$ Makromolekulare Chemie, Universität Freiburg, Stefan-MeierStrasse 31, 79100 Freiburg, Germany.

\section{Notes}

The authors declare no competing financial interest.

\section{ACKNOWLEDGMENTS}

The ESRF Grenoble and M. Sztucki are greatly acknowledged for the provision of synchrotron radiation facilities and assistance (beamline ID02). This work was carried out with the support of the Diamond Light Source, UK. V.S., R.T., and A.K. thank the DFG for financial support (KI-1094/3-1 and KI1094/4-1). M.S. is thankful to M. Thelakkat and H. W. Schmidt, University of Bayreuth, for the opportunity to carry out preliminary DSC measurements. S.H., R.H.F., M.S., and W.H. acknowledge the EPSRC for funding (grant number RG51308). P.K. and U.S. acknowledge the European Commission (NMP4-SL20010-246123) for funding. S.H. and P.K. are grateful to J. Clark, University of Cambridge, for fruitful discussions.

\section{REFERENCES}

(1) Handbook of Oligo- and Polythiophenes; Fichou, D., Ed.; WileyVCH: Weinheim, 2007.

(2) Heeney, M.; McCulloch, I. Flexible Electronics: Materials and Applications (Electronic Materials: Science \& Technology); Wong, W. S.; Salleo, A., Eds.; Springer: New York, 2009; pp 261-296.

(3) Katz., H. E.; Bao, Z.; Gilat, S. E. Acc. Chem. Res. 2001, 34, 359369.

(4) Salleo, A. Mater. Todav 2007, 10, 38-45.

(5) Osaka, I.; McCullough, R. D. Acc. Chem. Res. 2008, 41, 12021214.

(6) Yamamoto, T. NPG Asia Mater. 2010, 2, 54-60.

(7) Dang, M. T.; Hirsch, L.; Wantz, G. Adv. Mater. 2011, 23, 35973602 .

(8) Padinger, F.; Rittberger, R. S.; Sariciftci, N. S. Adv. Funct. Mater. 2003, 13, 85-88.

(9) Ma, W.; Yang, C.; Gong, X.; Lee, K.; Heeger, A. J. Adv. Funct. Mater. 2005, 15, 1617-1622.

(10) Reyes-Reyes, M.; Kim, K.; Carroll, D. L. Appl. Phys. Lett. 2005, $87,083506 / 1-3$.

(11) Li, G.; Shrotriya, V.; Huang, J.; Yao, Y.; Moriarty, T.; Emery, K.; Yang, Y. Nat. Mater. 2005, 4, 864-868.
(12) Lenes, M.; Wetzelaer, G.-J. A. H.; Kooistra, F. B.; Veenstra, S. C.; Hummelen, J. C.; Blom, P. W. M. Adv. Mater. 2008, 20, 21162119.

(13) Cheng, Y.-J.; Liao, M.-H.; Chang, C.-Y.; Kao, W.-S.; Wu, C.-E.; Hsu, C.-S. Chem. Mater. 2011, 23, 4056-4062.

(14) Zhao, G.; He, Y.; Li, Y. Adv. Mater. 2010, 22, 4355-4358.

(15) Bao, Z.; Dodabalapur, A.; Lovinger, A. J. Appl. Phys. Lett. 1996, $69,4108-4110$

(16) Ihn, K. J.; Moulton, J.; Smith, P. I. Polvm. Sci., Part B 1993, 31, 735-742.

(17) Chang, J.-F.; Clark, J.; Zhao, N.; Sirringhaus, H.; Breiby, D. W.; Andreasen, J. W.; Nielsen, M. M.; Giles, M.; Heeney, M.; McCulloch, I. Phys. Rev. B 2006, 74, 115318/1-12.

(18) Kline, R. J.; McGehee, M. D.; Kadnikova, E. N.; Liu, J.; Frechet, J. M. J.; Toney, M. F. Macromolecules 2005, 38, 3312-3319.

(19) Zen, A.; Pflaum, J.; Hirschmann, S.; Zhuang, W.; Jaiser, F.; Asawapirom, U.; Rabe, J. P.; Scherf, U.; Neher, D. Adv. Funct. Mater. 2004, 14, 757-764.

(20) Ballantyne, A. M.; Chen, L.; Dane, J.; Hammant, T.; Braun, F. M.; Heeney, M.; Duffy, W.; McCulloch, I.; Bradley, D. D. C; Nelson, J. Adv. Funct. Mater. 2008, 18, 2373-2380.

(21) Schilinsky, P.; Asawapirom, U.; Scherf, U.; Biele, M.; Brabec, C. I. Chem. Mater. 2005, 17, 2175-2180.

(22) Ma, W.; Kim, J. Y.; Lee, K.; Heeger, A. J. Macromol. Rapid Commun. 2007, 28, 1776-1780.

(23) Koppe, M.; Brabec, C. J.; Heiml, S.; Schausberger, A.; Duffy, W.; Heeney, M.; McCulloch, I. Macromolecules 2009, 42, 4661-4666.

(24) Kim, J. S.; Lee, Y.; Lee, J. H.; Park, J. H.; Kim, J. K.; Cho, K. Adv. Mater. 2010, 22, 1355-1360.

(25) Kim, Y.; Cook, S.; Kirkpatrick, J.; Nelson, J.; Durrant, J. R.; Bradley, D. D. C.; Giles, M.; Heeney, M.; Hamilton, R.; McCulloch, I. I. Phus. Chem. C 2007, 111, 8137-8141.

(26) Hiorns, R. C.; de Bettignies, R.; Leroy, J.; Bailly, S.; Firon, M.; Sentein, C.; Khoukh, A.; Preud'homme, H.; Dagron-Lartigau, C. Adv. Funct. Mater. 2006, 16, 2263-2273.

(27) Jiang, X. M.; Österbacka, R.; Korovyanko, O.; An, C. P.; Horovitz, B.; Janssen, R. A. J.; Vardeny, Z. V. Adv. Funct. Mater. 2002, 12, 587-597.

(28) Kim, Y.; Cook, S.; Tuladhar, S. M.; Choulis, S. A.; Nelson, J.; Durrant, J. R.; Bradley, D. D. C.; Giles, M.; McCullough, I.; Ha, C. S.; Ree, M. Nat. Mater. 2006, 5, 197-203.

(29) Woo, C. H.; Thompson, B., C.; Kim, B. J.; Toney, M. F.; Frechet, J. M. J. I. Am. Chem. Soc. 2008, 130, 16324-16329.

(30) Urien, M.; Bailly, L.; Vignau, L.; Cloutet, E.; de Cuendias, A.; Wantz, G.; Cramail, H.; Hirsch, L.; Parneix, J. Polym. Int. 2008, 57, 764-769.

(31) Mauer, R.; Kastler, M.; Laquai, F. Adv. Funct. Mater. 2010, 20, 2085-2092.

(32) McMahon, D. P.; Cheung, D. L.; Goris, L.; Dacun, J.; Salleo, A.; Troisi, A. J. Phys. Chem. B 2011, 115, 19386-19393.

(33) Sirringhaus, H.; Brown, P. J.; Friend, R. H.; Nielsen, M. M.; Bechgaard, K.; Langeveld-Voss, B. M.W.; Spiering, A. J. H.; Janssen, R. A. J.; Meijer, E. W.; Herwig, P.; de Leeuw, D. M. Nature 1999, 401, $685-688$

(34) Zhang, R.; Li, B.; Iovu, M. C.; Jeffries-EL, M.; Sauvé, G.; Cooper, J.; Jia, S.; Tristram-Nagle, S.; Smilgies, D. M.; Lambeth, N. D.; Kowalewski, T; McCullough, R. D. J. Am. Chem. Soc. 2006, 128, 3480-3481

(35) Crossland, E.; Rhami, K.; Reiter, G.; Steiner, U.; Ludwigs, S. Adv. Funct. Mater. 2011, 21, 518-524.

(36) Jimison, L. H.; Toney, M. F.; McCulloch, I.; Heeney, M.; Salleo, A. Adv. Mater. 2009, 21, 1568-1572.

(37) Mueller, C.; Zhigadlo, N., D.; Kumar, A.; Baklar, M., A.; Karpinski, J.; Smith, P.; Kreouzis, T.; Stingelin, N. Macromolecules 2011, 44, 1221-1225.

(38) Snyder, C. R.; Henry, J. S.; DeLongchamp, D. M. Macromolecules 2011, 44, 7088-7091.

(39) Mao, H.; Xu, B.; Holdcroft, S. Macromolecules 1993, 26, 11631169. 
(40) Pankaj, S.; Hempel, E.; Beiner, M. Macromolecules 2009, 42, 716-724.

(41) Yokoyama, A.; Yokozawa, T. Chem. Rev. 2009, 109, 5595-5619.

(42) Iovu, M. C.; Sheina, E. E.; Gil, R. R.; McCullough, R. D. Macromolecules 2005, 38, 8649-8656.

(43) Miyakoshi, R; Yokoyama, A.; Yokozawa, T. J. Am. Chem. Soc. 2005, 127, 17542-17547.

(44) Tkachov, R.; Senkovskyy, V.; Komber, H.; Sommer, J.-U.; Kiriy, A. I. Am. Chem. Soc. 2010, 132, 7803-7810.

(45) Zen, A.; Saphiannikova, M.; Neher, D.; Grenzer, J.; Grigorian, S.; Pietsch, U.; Asawapirom, U.; Janietz, S.; Schreff, U.; Lieberwirth, I.; Wegner, G. Macromolecules 2006, 39, 2162-2171.

(46) Wu, Z.; Petzold, A.; Henze, T.; Thurn-Albrecht, T.; Lohwasser, R. H.; Sommer, M.; Thelakkat, M. Macromolecules 2010, 43, 46464653.

(47) Ungar, G.; Zeng, X.-B. Chem. Rev. 2001, 101, 4157-4188.

(48) Zeng, X. B.; Ungar, G. Macromolecules 2001, 34, 6945-6954.

(49) Wilke, G.; Herrmann, G. Angew. Chem. Int. Ed. 1966, 5, 581582.

(50) Miyakoshi, R.; Yokoyama, A.; Yokozawa, T. Macromol. Rapid Commun. 2004, 25, 1663-1666.

(51) Lohwasser, R. H.; Thelakkat, M. Macromolecules 2011, 44, 3388-3397.

(52) Wu, S.; Huang, L.; Tian, H.; Geng, Y.; Wang, F. Macromolecules 2011, 44, 7558-7567.

(53) Tkachov, R.; Senkovskyy, V.; Komber, H.; Kiriy, A. Macromolecules 2011, 44, 2006-2015.

(54) Barbarella, G.; Bongini, A.; Zambianchi, M. Macromolecules 1994, 27, 3039-3045.

(55) Chen, T.-A.; Wu, X.; Rieke, R. D. J. Am. Chem. Soc. 1995, 117, 233-244.

(56) Lanni, E. L.; McNeil, A. I. Macromolecules 2010, 43, 8039-8044.

(57) Kaul, E.; Senkovskyy, V.; Tkachov, R.; Bocharova, V.; Komber, H.; Stamm, M.; Kiriy, A. Macromolecules 2010, 43, 77-81.

(58) Senkovskyy, V.; Tkachov, R.; Beryozkina, T.; Komber, H.; Oertel, U.; Horecha, M.; Bocharova, V.; Stamm, M.; Gevorgyan, S. A.; Krebs, F. C.; Kiriy, A. I. Am. Chem. Soc. 2009, 131, 16445-16453.

(59) Senkovskyy, V.; Sommer, M.; Komber, H.; Tkachov, R.; Huck, W.; Kiriy, A. Macromolecules 2010, 43, 10157-10161.

(60) Hanton, S. D. Chem. Rev. 2001, 101, 527-569.

(61) Bras, J.; Pépin-Donat, B. Magn. Reson. Chem. 2001, 39, 57-67.

(62) Prosa, T. J.; Winokur, M. J.; Moulton, J.; Smith, P.; Heeger, A. J. Macromolecules 1992, 25, 4364-72.

(63) Tashiro, K.; Ono, K.; Minagawa, Y.; Kobayashi, M.; Kawai, T.; Yoshino, K. J. Polym. Sci., Part B: Polvm. Phvs. 1991, 29, 1223-1233.

(64) Luo, C.-F.; Sommer, J.-U. Phvs. Rev. Lett. 2009, 102, 147801.

(65) Strobl, G. The Physics of Polymers, 3rd ed.; Springer: Berlin, Germany, 2007.

(66) Buckley, C. P.; Kovacs, A. I. Colloid Polvm. Sci. 1976, 254, 695715.

(67) Flory, P. J.; Vrij, A. I. Am. Chem. Soc. 1963, 85, 3548-3553.

(68) Pascui, O. F.; Lohwasser, R.; Sommer, M.; Thelakkat, M.; Thurn-Albrecht, T.; Saalwächter, K. Macromolecules 2010, 43, 94019410.

(69) Mena-Osteritz, E.; Meyer, A.; Langeveld-Voss, B. M. W.; Janssen, R. A. J.; Meijer, E. W.; Bäuerle, P. Angew. Chem. Int. 2000, 39, 2680-2684.

(70) Grévin, B.; Rannou, P.; Payerne, R.; Pron, A.; Travers, J. P. I. Chem. Phys. 2003, 118, 7097-7102.

(71) Sommer, J.-U. Eur. Phvs. I. E 2006, 19, 413-422.

(72) Malik, S.; Nandi, A. J. J. Polym. Sci., Part B: Polym. Phys. 2002, 40, 2073-2085.

(73) Flory, P. I. Trans. Faradav Soc. 1955, 51, 848-857.

(74) Sanchez, I. C.; Eby, R. K. Macromolecules 1975, 8, 638-641.

(75) Fischer, E. W.; Sterzel, H. J.; Wegner, G. Kolloid-Z. Z. Polym.

1973, 251, 980-990.

(76) Richardson, M. J.; Flory, P. J.; Jackson, J. B. Polymer 1963, 4, 221-236.
(77) Ungar, G.; Zeng, X. B.; Brooke, G. M.; Mohammed, S. Macromolecules 1998, 31, 1875-1879.

(78) Zeng, X.; Xie, F.; Ungar, G. Macromolecules 2007, 40, 57505758.

(79) De Ballesteros, O. R.; Auriemma, F.; Guerra, G.; Corradini, P. Macromolecules 1996, 29, 7141-7148.

(80) Wu, P.-T.; Ren, G.; Jenekhe, S. A. Macromolecules 2010, 43, 3306-3313.

(81) Souto Maior, R. M.; Hinkelmann, K.; Eckert, H.; Wudl, F. Macromolecules 1990, 23, 1268-1279.

(82) McCullough, R. D.; Tristram-Nagle, S.; Williams, S. P.; Lowe, R. D.; Jayaraman, M. I. Am. Chem. Soc. 1993, 115, 4910-4911.

(83) Yang, C.; Orfino, F. P.; Holdcroft, S. Macromolecules 1996, 29, 6510-6517.

(84) Spano, F. C. I. Chem. Phys. 2005, 122, 234701.

(85) Albert-Seifried, S.; Friend, R. H. Appl. Phvs. Lett. 2011, 98, 223304.

(86) Clark, J.; Chang, J.; Spano, F. C.; Friend, R. H.; Silva, C. Appl. Phys. Lett. 2009, 94, 163306.

(87) Spano, F. C. Acc. Chem. Res. 2010, 43, 429-439.

(88) Clark, J.; Silva, C.; Friend, R. H.; Spano, F. Phys. Rev. Lett. 2007, $98,206406$.

(89) Theander, M.; Svensson, M.; Ruseckas, A.; Zigmantas, D.; Sundström, V.; Andersson, M. R.; Inganäs, O. Chem. Phys. Lett. 2001, 337, 227-283.

(90) Kiriy, A.; Senkovskyy, V.; Sommer, M. Macromol. Rapid Commun. 2011, 32, 1503-1517.

(91) Senkovskyy, V.; Tkachov, R.; Komber, H.; Sommer, M.; Heuken, M.; Voit, B.; Huck, W. T. S.; Kataev, V.; Petr, A.; Kiriy, A. I. Am. Chem. Soc. 2011, 133, 19966-19970. 